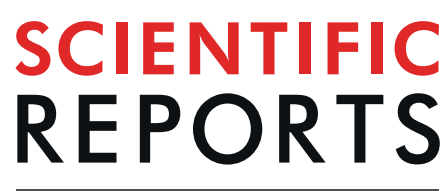

natureresearch

\title{
OPEN A human expression system based on HEK293 for the stable production of recombinant erythropoietin
}

Christine Lin Chin ${ }^{1,4}$, Justin Bryan Goh ${ }^{1,4}$, Harini Srinivasan ${ }^{2,3}$, Kaiwen Ivy Liu ${ }^{3}$, Ali Gowher ${ }^{3}$, Raghuvaran Shanmugam ${ }^{3}$, Hsueh Lee Lim ${ }^{1}$, Matthew Choo ${ }^{1}{ }^{1}$, Wen Oin Tang ${ }^{1}$, Andy HeeMeng $\operatorname{Tan}^{1}$, Terry Nguyen-Khuong ${ }^{1}$, Meng How Tan $\mathbb{1}^{2,3^{*}}$ \& Say Kong Ng $\mathbb{D}^{1^{*}}$

Mammalian host cell lines are the preferred expression systems for the manufacture of complex therapeutics and recombinant proteins. However, the most utilized mammalian host systems, namely Chinese hamster ovary (CHO), Sp2/0 and NSO mouse myeloma cells, can produce glycoproteins with non-human glycans that may potentially illicit immunogenic responses. Hence, we developed a fully human expression system based on HEK293 cells for the stable and high titer production of recombinant proteins by first knocking out GLUL (encoding glutamine synthetase) using CRISPRCas9 system. Expression vectors using human GLUL as selection marker were then generated, with recombinant human erythropoietin (EPO) as our model protein. Selection was performed using methionine sulfoximine (MSX) to select for high EPO expression cells. EPO production of up to $92700 \mathrm{U} /$ $\mathrm{mL}$ of EPO as analyzed by ELISA or $696 \mathrm{mg} / \mathrm{L}$ by densitometry was demonstrated in a $2 \mathrm{~L}$ stirred-tank fed batch bioreactor. Mass spectrometry analysis revealed that $\mathrm{N}$-glycosylation of the produced EPO was similar to endogenous human proteins and non-human glycan epitopes were not detected. Collectively, our results highlight the use of a human cellular expression system for the high titer and xenogeneic-free production of EPO and possibly other complex recombinant proteins.

Mammalian cells have been used for the production of recombinant protein therapeutics for over three decades to-date due to the requirement of post-translational modifications (PTMs) for activity ${ }^{1}$. Thus far, mammalian cell lines approved for the manufacture of recombinant protein therapeutics include Chinese hamster ovary $(\mathrm{CHO})$ cells, baby hamster kidney (BHK) cells, Sp2/0 murine hybridoma cells, NS0 murine myeloma cells, C127 murine mammary gland cells, HT-1080 human fibrosarcoma cells and human embryonic kidney cells 293 (HEK293) ${ }^{2}$. $\mathrm{CHO}$ cells are the dominant mammalian host cell lines used for the manufacture of recombinant protein therapeutics ${ }^{1}$ due to a number of advantages: (1) CHO cells confer human-like glycosylation features to glycoprotein products, (2) are capable of high protein productivity with titers up to grams per liter due to established stable cell line generation strategies, (3) propagate well in serum-free single-cell suspension cultures enabling ease of scale-up, (4) are refractory to a number of human viruses providing lower biosafety risks, and (5) have established regulatory track records for the manufacture of recombinant protein therapeutics ${ }^{3-6}$. Nevertheless, $\mathrm{CHO}$ cells have been reported to generate non-human glycan structures including N-glycolylneuraminic acid (Neu5Gc) and galactose-alpha-1,3-galactose group ( $\alpha$-Gal) onto glycoprotein products which confers increased risk of immunogenicity ${ }^{7,8}$. CHO-derived glycoproteins also lack certain human glycans, including bisecting GlcNAc, Lewis ${ }^{\mathrm{x}}$, sialyl Lewis ${ }^{\mathrm{x}}$, and $\alpha(2,6)$-linked sialic acid ${ }^{6,8}$. Moreover, CHO cells may not adequately produce other PTMs (such as glutamic acid $\gamma$-carboxylation) required for activity of some recombinant protein therapeutics 9 .

In efforts to obtain more human-like protein therapeutics, pharmaceutical companies have utilized various human cell lines, such as HEK293, HT-1080, AGE1.HN, CAP, HKB-11 and PER.C6 for glycoprotein

\footnotetext{
${ }^{1}$ Bioprocessing Technology Institute, Agency for Science, Technology and Research (A*STAR), Singapore, Singapore. ${ }^{2}$ School of Chemical and Biomedical Engineering, Nanyang Technological University, Singapore, Singapore. ${ }^{3}$ Genome Institute of Singapore, Agency for Science, Technology and Research (A*STAR), Singapore, Singapore. ${ }^{4}$ These authors contributed equally: Christine Lin Chin and Justin Bryan Goh. *email: mh.tan@ntu.edu.sg; ng_say_ kong@bti.a-star.edu.sg
} 
production ${ }^{2,8}$. While products from AGE1.HN, CAP, HKB-11 and PER.C6 are still at different phases of preclinical and clinical development, several protein therapeutics from HEK293 and HT-1080, including recombinant factor VIII-Fc, Dulaglutide, Idursulfase and Velaglucerase alfa have already been approved by the US Food and Drug Administration (FDA) and European Medicines Agency (EMA) ${ }^{2}$. These regulatory approvals for HEK293 and HT-1080 demonstrate successful circumvention of potential biosafety risks from human virus contamination and provide a useful basis for future assessment of other therapeutics produced using human cell lines.

HEK293 cells are a particularly attractive expression system for recombinant protein production as they offer multiple advantages besides being able to generate human glycosylation profiles and having an established regulatory track record. First, it is exceptionally efficient in glutamic acid $\gamma$-carboxylation and tyrosine sulfation, which is required of some therapeutic products like Drotrecogin alfa and recombinant factor IX-Fc ${ }^{2,9-11}$. Second, it is easily manipulated and can be used for rapid production of recombinant proteins via transient gene expres$\operatorname{sion}^{12,13}$. Third, it can be used for stable recombinant protein production, which has been reported for IFN $\alpha 2 b$ using HEK293-6E cells with titers of up to $333 \mathrm{mg} / \mathrm{L}^{14}$ and antibodies using HEK293F cells with titers of up to $600 \mathrm{mg} / \mathrm{L}^{15}$.

Despite the potential of HEK293 as a human bioproduction cell line, stable recombinant protein production in HEK293 has been achieved mainly using xenogeneic genes as selection markers. For example, HEK293-6E cells constitutively expressing the non-native Epstein-Barr virus (EBV) EBNA1 protein have been utilized for the amplification of expression vectors with a suitable viral origin of replication ${ }^{14}$. Antibiotic selection strategies involving resistance cassettes from other organisms have also been deployed. The usage of xenogeneic genes will result in higher expression of non-human proteins in the HEK293 producer cell lines on top of the E1 adenoviral genes that the HEK293 expresses, and potentially trace amounts of these proteins can contaminate the final product. Such contamination may trigger allergic and adverse reactions, and/or immunogenicity to the product.

To offer a bioproduction system with low expression of heterologous proteins, we explored the use of human glutamine synthetase (GLUL) gene as a selection marker for the development of producer cell lines. Glutamine is an amino acid required for the biosynthesis of several amino acids, pyrimidines and purines, and it can be synthesized from glutamate and ammonia by GLUL or can be exogenously supplemented to culture medium to support cell growth. As a selection marker, GLUL expression becomes essential in the absence of glutamine in the culture media. Coupled with the expression of the transgene-of-interest and upon addition of sub-lethal doses of methionine sulfoximine (MSX), a GLUL inhibitor, cells expressing high levels of GLUL with simultaneously increased expression of the target transgene were selected for. This GLUL-mediated gene selection strategy was first demonstrated in $\mathrm{CHO}$ cells ${ }^{16}$, and subsequently implemented in HEK293E cells but with low titers ${ }^{17,18}$. In this study, we knocked out the endogenous GLUL gene in HEK293 cells using the CRISPR-Cas9 system, characterized the cells by RNA sequencing (RNA-seq), and demonstrated the utility of our bioproduction platform for the production of human erythropoietin (EPO) as a model product. High producer cells, selected using MSX in glutamine-deficient media, were characterized in batch shake flask and fed-batch bioreactor cultures.

\section{Results}

Inactivation of GLUL in HEK293 cells using CRISPR-Cas9. In order to prevent endogenous GLUL protein from interfering with our gene selection strategy as observed in a previous report ${ }^{17}$, we sought to knock out the native GLUL gene in HEK293 using the CRISPR-Cas9 system. Two guide RNAs (gRNAs) were designed to target the first constitutive protein-coding exon (Fig. 1a) which would inactivate all isoforms simultaneously. Following transfection with the Cas 9 and gRNA plasmids, we selected for the successfully transduced cells by flow cytometry and then plated the sorted cells sparsely on a plate to allow single cells to grow up as individual colonies. After picking and expanding multiple individual clones, we screened all of them for loss of GLUL protein by Western blot and identified four clones where the protein was absent (Fig. 1b). Subsequently, we sequenced the target genomic locus of the four clones. For clones \#7, \#20, and \#24, two distinct alleles were found in each of them (Fig. 1c). In clone \#7, we detected one allele with $14 \mathrm{bp}$ deletion and another allele with $47 \mathrm{bp}$ deletion; in clone \#20, we uncovered two different $47 \mathrm{bp}$ deletions; and in clone \#24, we detected one allele with $47 \mathrm{bp}$ deletion and another allele with 48 bp deletion. Lastly, for clone \#29, we uncovered five distinct alleles (Fig. 1c), suggesting that the clone may have grown a merged colony containing two or more single cells. All observed mutations except the $48 \mathrm{bp}$ deletion resulted in frameshifts, which may trigger nonsense-mediated decay of the GLUL transcript ${ }^{19}$. Consequently, gene expression analysis by quantitative real-time PCR (qPCR) showed that GLUL transcript levels were indeed significantly down-regulated in all four clones (Fig. 1d). To verify the loss of GLUL function in our knockout clones, we monitored the growth rates of the cells in media either supplemented with or deficient of glutamine. Glutamine dependency screening was previously used in CHO, NS0 and HEK293E cell lines to identify clones lacking active GLUL protein ${ }^{18,20}$. Here, we observed that there was no clear difference in growth rate between wildtype HEK293 cells and all the $G L U L^{-1-}$ clones in glutamine-supplemented media with all the cell lines reaching over $90 \%$ confluency within 6 days (Fig. 1e, left panel). However, our generated $G L U L^{-1-}$ clones were unable to proliferate in glutamine-deficient media, unlike the original wildtype HEK293 cells (Fig. 1e, right panel), thereby verifying that we had successfully inactivated the GLUL gene.

As part of the process to utilize our novel $G L U L^{-1-}$ cell lines for bioproduction, we adapted them to suspension serum-free culture together with the wildtype HEK293 cells. Immunoblot analysis at this stage again confirmed that the GLUL protein was absent in our knockout clones (Fig. 1f). We also characterized the growth profiles of the cells in culture media with or without glutamine (Fig. 1g). Overall, wildtype and $G L U L^{-1-}$ cells propagated slower in suspension compared to adherent culture. In glutamine-supplemented media, $G L U L^{-1-}$ cells clones \#7 and \#24 grew slightly faster than wildtype HEK293 cells, while clones \#20 and \#29 had similar growth profiles compared to wildtype HEK293 cells, with the various cell lines reaching viable cell densities (VCD) of approximately 3 to $5 \times 10^{6}$ cells/mL on day 6 of the batch culture (Fig. $1 \mathrm{~g}$, left panel). In glutamine-deficient media, while we observed slower growth for wildtype HEK293 cells (reaching cell densities of only $1 \times 10^{6} \mathrm{cells} / \mathrm{mL}$ at day 7), 


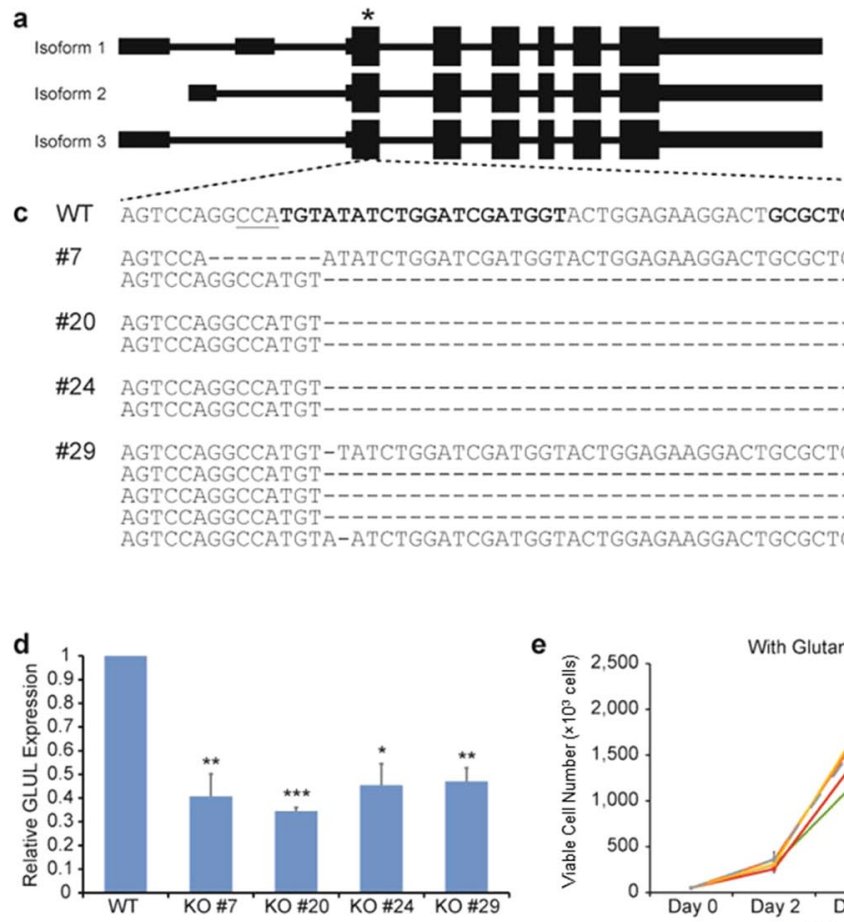

b

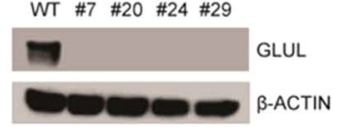

WT A.GTCCAGGCCATGTATATCTGGATCGATGGTACTGGAGAAGGACTGCGCTGCAAGACCCGGACCCTGGACAGTGAGCCCAAGTGT

\$2 AGTCCA-------ATATCTGGATCGATGGTACTGGAGAAGGACTGCGCTGCAAGACCC------TGGACAGTGAGCCCAAGTGT

作

作

AGTCCAGGCCATGT -TATCTGGATCGATGGTACTGGAGAAGGACTGCGCTGCAAGACC-1-10 AGTCCAGGCCATGT AGTCCAGGCCATGTAGTCCAGGCCATGTA-ATCTGGATCGATGGTACTGGAGAAGGACTGCGCTGCAAGACCCG--CCCTGGACAGTGAGCCCAAGTGT $\uparrow$
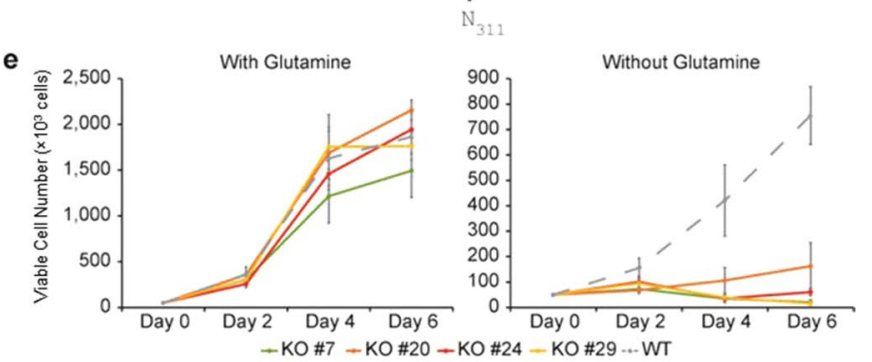

f
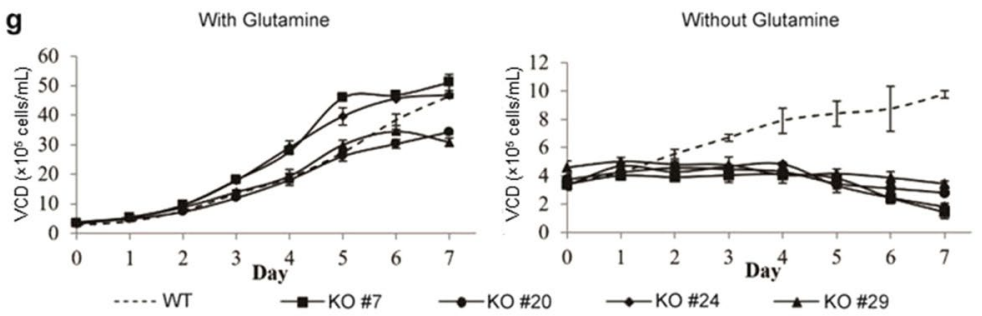

Figure 1. Generation of HEK293 GLUL knockout (KO) cells. (a) Schematic of the three GLUL isoforms. HEK293 wildtype (WT) cells were transfected with vectors encoding Cas9 and two gRNAs targeting the first constitutive protein-coding exon of the GLUL gene. The target site is indicated with an asterisk. (b) Immunoblots showing the presence of GLUL protein in wildtype cells, but absence of protein in four isolated KO clones, cultivated as adherent cultures. (c) GLUL sequence at the target site. The spacer sequences of the gRNAs are indicated in bold, while the protospacer adjacent motifs (PAMs) of Cas9 from Streptococcus pyogenes (SpCas9) are underlined. The two gRNAs target opposite strands of the genomic DNA. (d) Relative expression of GLUL in WT and KO cells, as assayed by qPCR. Values represent mean \pm S.E.M. $(* \mathrm{P}<0.05, * * \mathrm{P}<0.01$ $* * * \mathrm{P}<0.001$; Student's t-test) (e) Sensitivity of WT and KO cells to glutamine-deficient media. WT cells are indicated by a dotted line, while the four KO clones are indicated by solid colored lines. The cells were grown in adherent culture conditions. Values represent mean \pm S.E.M. (f) Immunoblots showing the presence of GLUL protein in wildtype cells, but absence of protein in four isolated $\mathrm{KO}$ clones cultivated in suspension culture conditions. (g) Sensitivity of WT and KO cells to glutamine-deficient media. WT is represented in a broken line, while GLUL-KO \#7 (square), \#20 (circle), \#24 (diamond), and \#29 (triangle) are depicted in solid lines and symbols. The cells were grown in suspension culture conditions. Values represent mean \pm SD.

all four $G L U L^{-1-}$ clones were unable to proliferate (Fig. 1g, right panel), thereby confirming the functional loss of GLUL in these knockout cell lines.

Transcriptome analysis of GLUL knockout cell lines. To gain insights into the molecular changes in our GLUL knockout clones during adherent and suspension culture, we analyzed their transcriptomes by RNA-seq on the Illumina platform. We sequenced poly(A)-selected RNAs isolated from all four $G L U L^{-1-}$ cell lines and the wildtype HEK293 cells from adherent and suspension cultures during exponential phase, and obtained between 19 to 147 million paired-end reads for each sample. Expression counts were calculated using DESeq2 ${ }^{21}$. Principal component analysis (PCA) (Fig. 2a) and clustering analysis based on Euclidean distance (Fig. 2b) revealed that the samples separated by experimental conditions and that the differences between wildtype and knockout cells were larger than the differences between adherent and suspension cultures.

First, we compared all the wildtype samples against all the $G L U L^{-1-}$ samples, pairing the culture conditions in our analysis, where 915 and 1,142 genes were significantly up-regulated and down-regulated in the $G L U L^{-1-}$ cells 
a

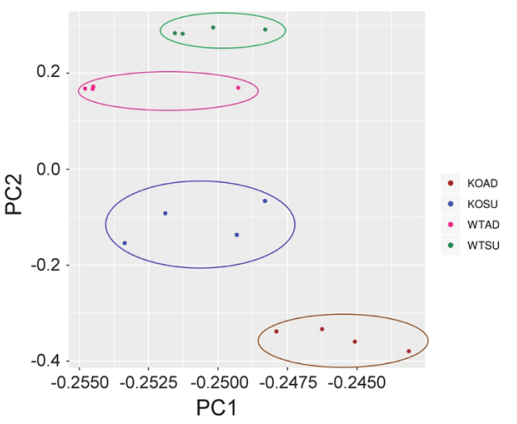

b

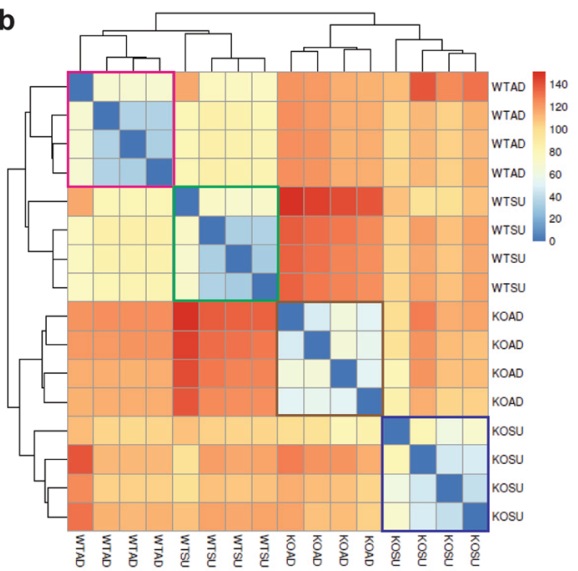

C

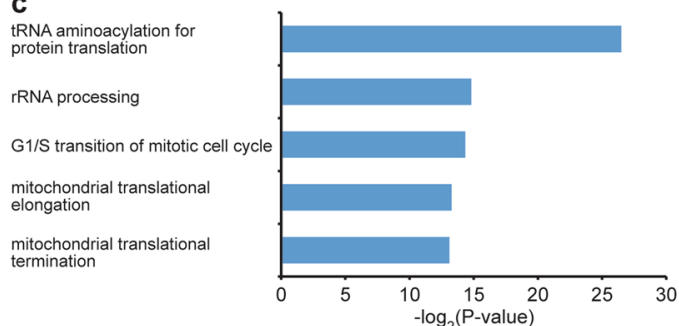

e

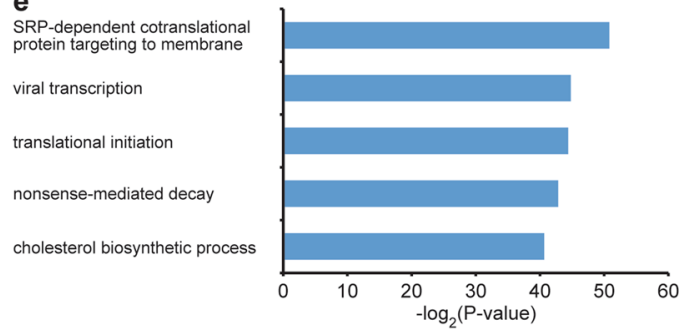

d

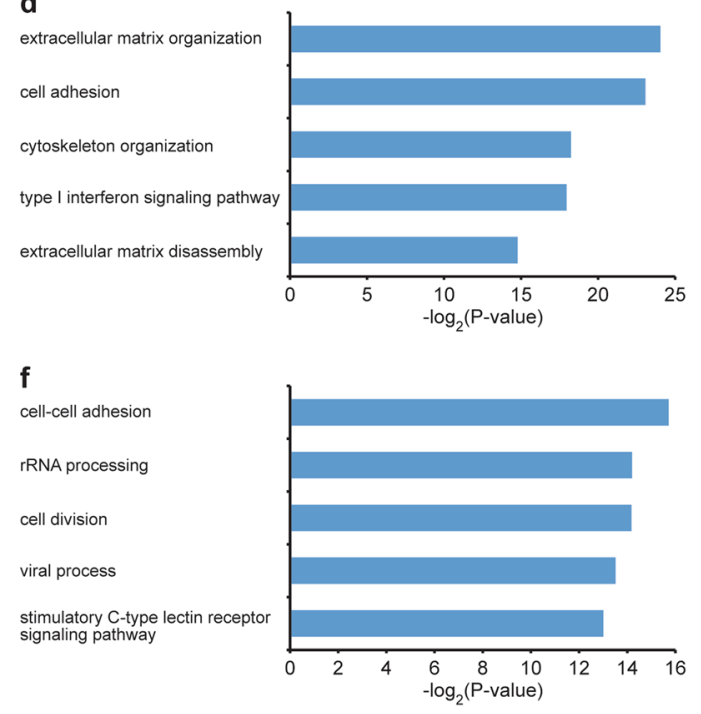

Figure 2. Transcriptome analysis of HEK293 WT and GLUL-KO cells. (a) PCA of gene expression levels. Four biological replicates were generated for the original WT cells grown under each culture condition (adherent or suspension). (b) Hierarchical clustering of our gene expression data. The heatmap showed that the various samples first separated based on GLUL gene status (i.e. GLUL $L^{+/+}$or $G L U L^{-/-}$) and then by culture condition (adherent or suspension). The values of the heatmap are Euclidean distances. (c,d) GO analysis of the genes that were significantly (c) up-regulated or (d) down-regulated in our $\mathrm{KO}$ clones when compared to the unmodified WT cells (adjusted $\mathrm{P}<0.0001)$. (e,f) GO analysis of the genes that were significantly (e) up-regulated or $(\mathbf{f})$ down-regulated in suspension cells when compared to adherent cells (adjusted $\mathrm{P}<0.0001$ ).

respectively (adjusted P-value $<0.0001$ ) (Supplementary File 1). Interestingly, Gene Ontology (GO) analysis using DAVID ${ }^{22}$ revealed that the up-regulated genes were significantly enriched for functions related to protein translation (Fig. 2c), possibly in response to the loss of GLUL, a key enzyme involved in amino acid metabolism. Additionally, the down-regulated genes were significantly enriched for functions related to the extracellular matrix, cell adhesion, cytoskeleton, and interferon signaling (Fig. 2d).

Second, we compared all the adherent samples against all the suspension samples, pairing the GLUL gene status in our analysis- 549 and 596 genes were significantly up-regulated and down-regulated in the cells grown in suspension culture respectively (adjusted P-value $<0.0001$ ) (Supplementary File 2). GO analysis using DAVID ${ }^{22}$ revealed that the up-regulated genes were significantly enriched for functions related to the cell membrane and RNA metabolism (Fig. 2e), perhaps reflecting the fact that the cells were no longer attached to a surface and therefore required remodeling of the cell envelope. Expectedly, we also found that the down-regulated genes were enriched for functions related to cell-cell adhesion and cell division (Fig. 2f), which may account for the slower growth rates in suspension cultures. Collectively, our transcriptome analysis uncovered molecular changes that were consistent with observed phenotypes and we also did not detect any strong gene signature that might indicate alterations in protein glycosylation in the $G L U L^{-1}$ cells that might affect their use as a platform for the manufacture of glycoproteins.

Productivity and production stability of HEK293 EPO-producing cell lines. Following the characterization of our $G L U L^{-1-}$ cells, we sought to demonstrate their utility in bioproduction, using human EPO 

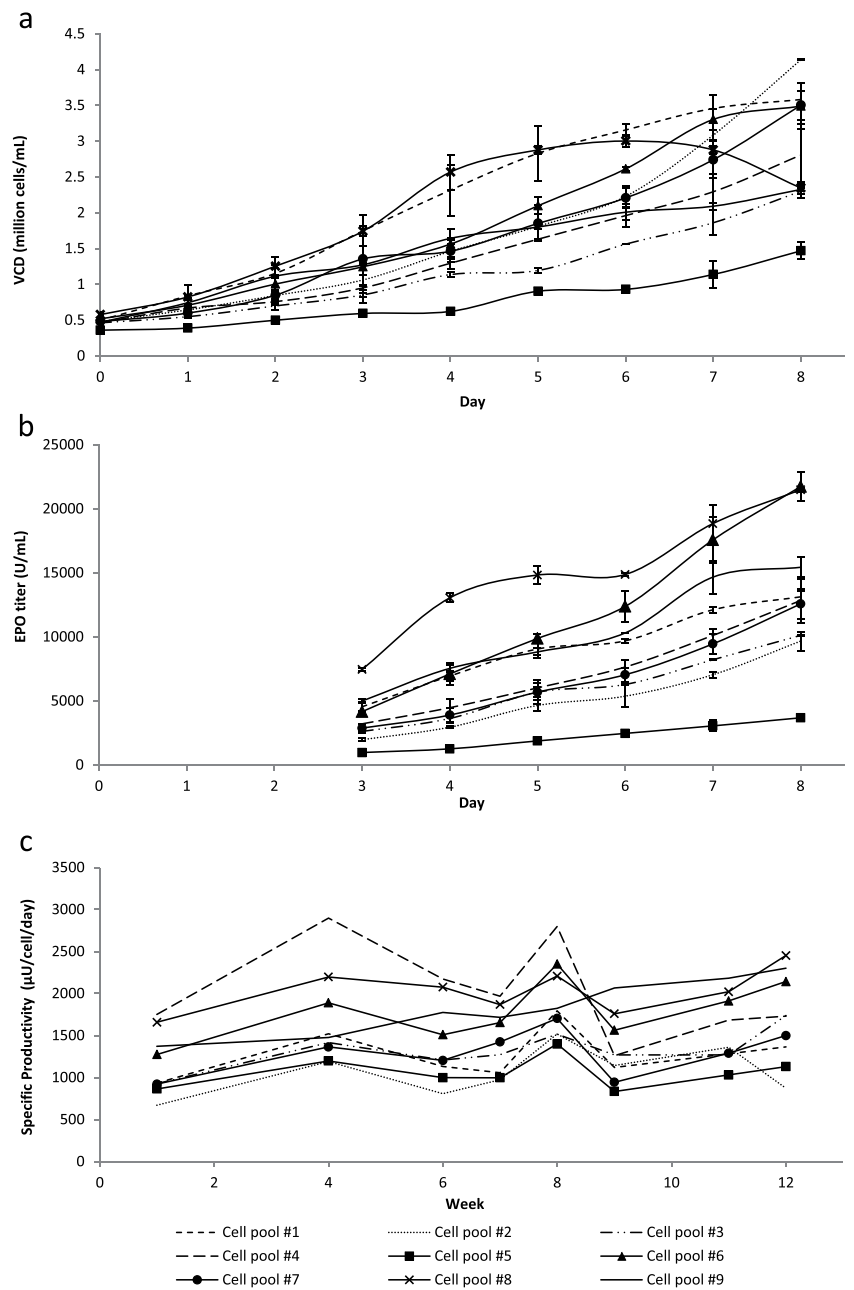

Figure 3. Production and stability of EPO of HEK293 producer cells. GLUL-KO clones were transfected with bicistronic vector expressing human GLUL and human EPO cultured in glutamine-deficient media. Postmethionine sulfoximine (MSX) selection, nine cell pools were generated and characterized for (a) viable cell density and (b) EPO production. Values represent mean \pm SD (c) MSX selection was subsequently removed from culture for stability testing over 12 weeks with specific productivity measured at day 4 cultures. $(n=2)$.

as a model product. Knockout cells were transfected with a bicistronic vector expressing human GLUL and human EPO. MSX, a potent inhibitor of GLUL activity, was then used for gene selection and high expression of GLUL-based expression vectors ${ }^{23,24}$. Selection with MSX based on previous reports using CHO and NS0 cell lines span a wide range from $25 \mu \mathrm{M}$ to $1000 \mu \mathrm{M}^{24-27}$. For a related study in a HEK293E GLUL $^{-1-}$ cell line, $12.5 \mu \mathrm{M}$ of MSX was used to select for GLUL-based expression vectors to $\mathrm{mAb}$ yields of about $8 \mathrm{mg} / \mathrm{L}$ with specific productivity of about $4.5 \mathrm{pcd}$ (picogram/cell/day) ${ }^{18}$. In comparison, we were able to obtain high-producer HEK-EPO mini-pools with $100 \mathrm{nM}$ MSX, possibly due to the attenuation of GLUL gene in the expression vector ${ }^{28,29}$. A total of 175 mini-pools were generated from the selection process and 9 were subsequently adapted to suspension cultures. In a batch shake flask culture, maximum viable cell densities of these mini pools range from $1.4 \times 10^{6}$ to $4.1 \times 10^{6}$ cells $/ \mathrm{mL}$, with EPO titers ranging from 3680 to $21730 \mathrm{U} / \mathrm{mL}$ (Fig. 3a,b). The highest producers, cell pools \#8 and \#6, achieved EPO titers of 21480 and $21730 \mathrm{U} / \mathrm{mL}$ and a maximum viable cell density of $3.0 \times 10^{6}$ cells $/ \mathrm{mL}$ and $3.5 \times 10^{6}$ respectively.

Production stability is an important consideration for selecting a suitable cell line in biotherapeutics manufacturing, especially in view of recent interests in long-term perfusion cultures. Previous studies have conflicting reports on the stability of GLUL-based selection systems, which may be clone dependent: A stability study of over 30 passages carried out in mAb-producing $\mathrm{CHO}$ cells showed most clones decreased in productivity when cultured either in the presence or absence of 25-50 $\mu \mathrm{M}$ MSX treatments although stable clones can be obtained ${ }^{24}$. Decrease in productivity was similarly reported in other CHO-mAb producing cell lines, especially when MSX was withdrawn from the culture $27,30,31$. In another report using GLUL deficient NS0 cells, recombinant protein production with GLUL-based vectors was demonstrated to be stable in 2 out of 4 clones analyzed over 134 days of passaging ${ }^{32}$.

In this study, the stability of HEK-EPO cell pools were assessed to analyze the general production stability of cells developed using this system. As cell pools are heterogeneous cell populations, these will be representative 
of large subsets of cells, in contrast to the use of single cell clones which will reflect clonal variability of cell pools they were derived from. The cell pools were passaged in media deficient of MSX over a period of 12 weeks. From VCD and titer analysis of day 4 samples at each selected passage, it was noteworthy to observe that all 9 production cell pools retained production stability throughout the 12-week period (Fig. 3c) with specific productivities ranging from $99 \%$ to $187 \%$ at week 12 compared to week 1 . This suggests that the GLUL-MSX selection system in these HEK293 GLUL ${ }^{-1-}$ cells generates production cell lines that are generally stable in recombinant protein productivity. This is interesting in light of challenges to obtain stable clones as described above, because the results suggest that stable clones can be easily obtained using this system. We postulate that this may be due to the low MSX concentration used for selection in this study. Improvements in specific productivities over 12 weeks without MSX were also observed for 8 out of the 9 cell pools. This can be attributed to cell pools adapting well to a less selective culture medium which allowed for better cell growth and increased titer. As cell pool \# 8 was one of the highest producer throughout the period of 12 weeks with a more stable specific productivity profile, we selected cell pool \#8 for further analysis and production of EPO in bioreactor cultures.

Nucleic acid analysis of EPO-producing cell pool. To characterize cell pool \#8, we compare its gene copy number of endogenous and exogenous GLUL and EPO to that in wildtype and $G L U L^{-1-}$ cells via droplet digital PCR (ddPCR). While HEK293 wildtype cells showed basal levels of endogenous GLUL, GLUL ${ }^{-l-}$ cells showed absence of GLUL following disruption with CRISPR-Cas9, since one primer probing for endogenous GLUL was designed to be on the gRNA target region. Post GLUL-vector transfection and MSX selection, relative positive ddPCR counts in cell pool \#8 showed an exogenous GLUL copy number that was four-fold that of the endogenous GLUL in wildtype cells (Fig. 4a, left panel). Analysis of EPO showed endogenous basal copy numbers in all three cell lines analyzed. For the stably transfected cell pool \#8, it showed an exogenous EPO level that was about four-fold higher than endogenous EPO copy numbers in wildtype cells (Fig. 4a, right panel), fairly consistent with the copy numbers observed for exogenous GLUL.

At the transcript level, while we observed low levels of GLUL mRNA expression in wildtype cells at 2.2 copies/ng RNA, practically no expression of GLUL mRNA was detected in $G L U L^{-/-}$cells $(<0.005$ copies/ng RNA) because one primer probing for endogenous GLUL was designed to be in the region targeted by the gRNA. Very low expression of EPO mRNA in wildtype and $G L U L^{-1-}$ cells $(<0.32$ copies/ng RNA) was also detected. On the other hand, cell pool \#8 showed similar expression levels of exogenous GLUL and EPO mRNA at 12,300 and 10,000 copies per ng RNA respectively, using $R P L P 0$ as a reference gene (Fig. $4 \mathrm{~b}$, left and right panel respectively). These represent a 5,500-fold increase in exogenous GLUL mRNA expression and a 31,000 fold increase in exogenous EPO mRNA expression compared to total expression in wildtype HEK293 cells. The observed increase in GLUL and EPO mRNA expression is significantly greater than the increase in GLUL and EPO genomic copy number, suggesting the successful selection of a cell pool with transgene insertions into transcriptionally active sites and/or a more robust transcription machinery.

Increased translation to protein was also observed: Immunoblot analysis showed basal expression of the GLUL protein in wildtype HEK293 cells, no expression in the $G L U L^{-1-}$ cells and an increased GLUL expression in cell pool \#8 (Fig. 4c, left panel). As for EPO protein, expression was only detected in supernatant from cell pool \#8 but not in supernatant from wildtype HEK293 and GLUL ${ }^{-1-}$ cultures (Fig. 4c, right panel). Taken together, these results from increased gene copy number to final protein expression demonstrated the successful selection of an EPO producing cell pool using our GLUL-MSX selection system comprising of HEK293 GLUL ${ }^{-1-}$ cells and expression vector with human GLUL selection marker.

EPO production in fed-batch culture. The ability to achieve effective production of a desired protein in a large-scale manufacture is key for commercial success. To demonstrate potential scalability, we performed a fed-batch culture using HEK-EPO cell pool \#8 in a $2 \mathrm{~L}$ stirred tank bioreactor (Fig. 5). In the bioreactor, average specific growth rate was $0.0134 \mathrm{~h}^{-1}$, reaching average maximum VCD of $10.2 \times 10^{6} \mathrm{cells} / \mathrm{mL}$ on day 10 (Fig. 5a). Fed-batch culture of the cell pool generated in this study was capable of producing $92700 \mathrm{U} / \mathrm{mL}$ of EPO as analyzed by ELISA or $696 \mathrm{mg} / \mathrm{L}$ by densitometry (Fig. 5b and Supplementary Fig. 1), with maximum specific productivities of $4070 \mu \mathrm{U} / \mathrm{cell} /$ day or $18.1 \mathrm{pcd}$. As such, titers achieved in our study are comparatively superior to previous reports on recombinant EPO production (Table 1).

Daily analysis of metabolites in the bioreactor supernatant showed a gradual glucose consumption over time during exponential cell growth till day 10 when growth plateaued (Fig. 5c). Glutamine, being an essential energy source and nitrogen donor for cells in vitro, was excluded from our media to put selection pressure on cells. This helps to ensure that only cells with high expression of GLUL and subsequent production of EPO would be able to survive. Glutamine concentration, although starting at $0 \mathrm{mM}$, was observed to increase over time from day 4 and reached a peak of $3.3 \mathrm{mM}$ at day 9 (Fig. $5 \mathrm{~d}$ ). Since culture viability was above $88 \%$ throughout the 10 -day culture, we postulate that the increase in glutamine levels was due to the increase in cell density and as such GLUL concentrations in the bioreactor over time. This may have resulted in increased conversion of glutamate into glutamine by GLUL above that needed by the cells to result in increased glutamine concentration. Evidence that this glutamate to glutamine conversion is essential for $G L U L^{-1-}$ cells to grow was observed at day 7 of culture where exponential growth of the cells almost depleted the supply of glutamate in the media (Fig. 5e). Since glutamate is one of the limiting factors in the growth of $G L U L^{-1-}$ cells, this deficiency was rectified via the addition of feed media to maintain cell growth and viability. Accumulation of growth-inhibiting metabolites, lactate and ammonia, were minimal in our bioreactor runs, reaching maximum values of $1.5 \mathrm{~g} / \mathrm{L}$ and $0.8 \mathrm{mM}$ respectively (Fig. $5 f, \mathrm{~g}$ ). In contrast, consumption of lactate and ammonia was observed on day 4 and day 7 respectively. The consumption of ammonia coincided with the decrease in glutamate and increase in glutamine, suggesting that glutamate is being converted to glutamine due to the GLUL expression. This is consistent with previous report ${ }^{33}$. Osmolality was also maintained at physiological levels (between 277 and $302 \mathrm{mOsm} / \mathrm{kg}$ ) during the 10 days duration of the 
a
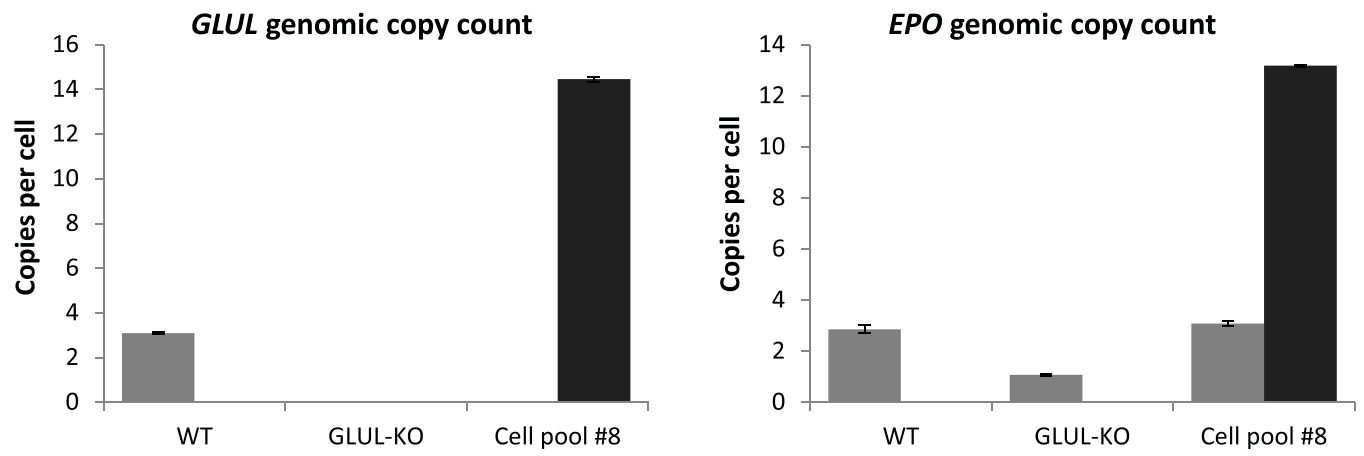

Endogenous Exogenous

$\mathrm{b}$
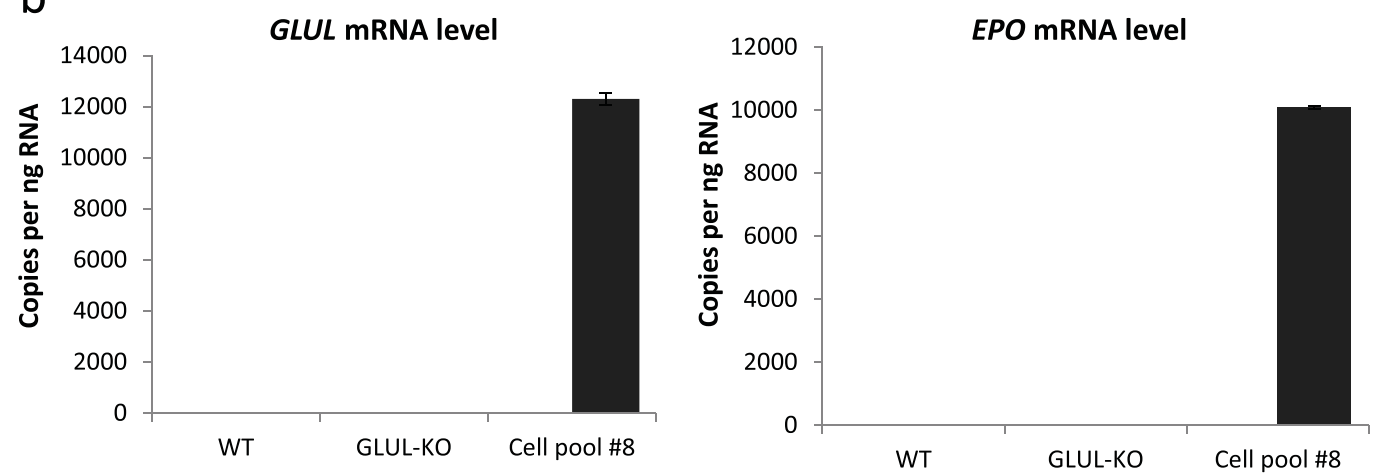

Endogenous Exogenous

C

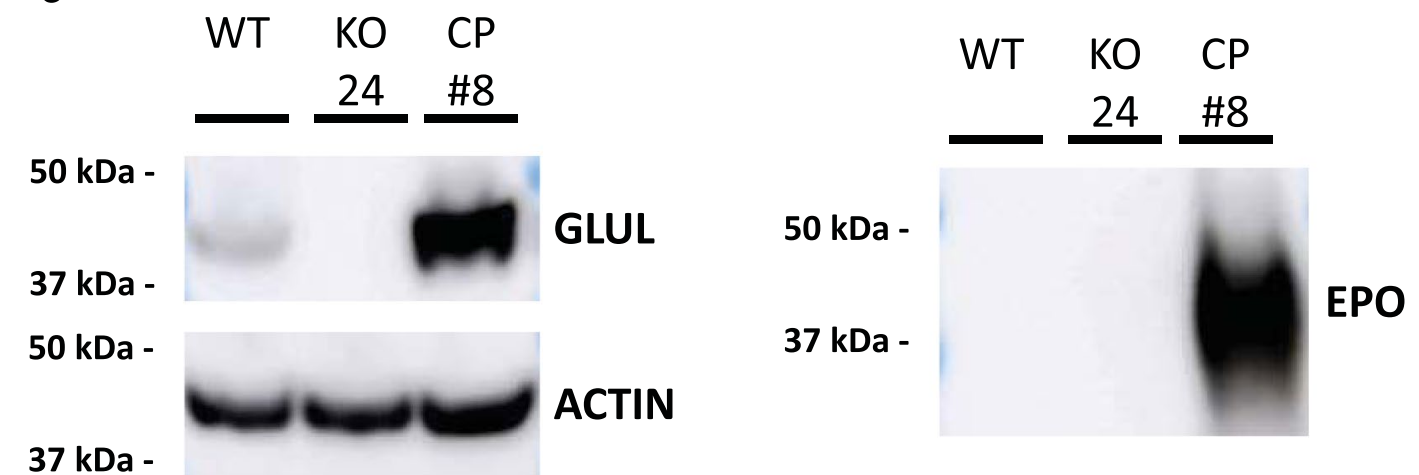

Figure 4. Characterization of EPO expression in GLUL-MSX-mediated HEK293 producer cell pool. (a) Endogenous (light gray bars) and exogenous (dark gray bars) GLUL and EPO genomic DNA copy count analyzed via droplet digital PCR (ddPCR). Values represent mean \pm SD (b) Endogenous (light gray bars) and exogenous (dark gray bars) GLUL and EPO mRNA copy count analyzed via ddPCR. Values represent mean \pm SD (c) Immunoblot of GLUL and EPO protein in HEK293 wildtype (WT), GLUL-KO (KO \#24) and cell pool \#8 (CP\#8). Actin was used as a loading control.

run (Fig. 5h). These data suggest that growth and production of EPO during the bioreactor run was not hindered by the analyzed metabolites.

Glycosylation analysis of HEK293-derived EPO. To understand the glycosylation micro- and macroheterogeneity of the EPO produced from the HEK-EPO cell pool, site-specific glycopeptide analysis of the EPO harvested from Day 10 of the bioreactor culture was carried out (Fig. 6). Depicted are relative abundances determined by integrating the extracted ion chromatograms for each glycopeptide measured on the mass spectrometer. The HEK-derived EPO was heavily sialylated on both $\mathrm{N}$-glycosylation and O-glycosylation, with on average 6.55 NeuAc per mole of EPO (Table 2). This degree of sialylation was similar to that of EPO produced in 

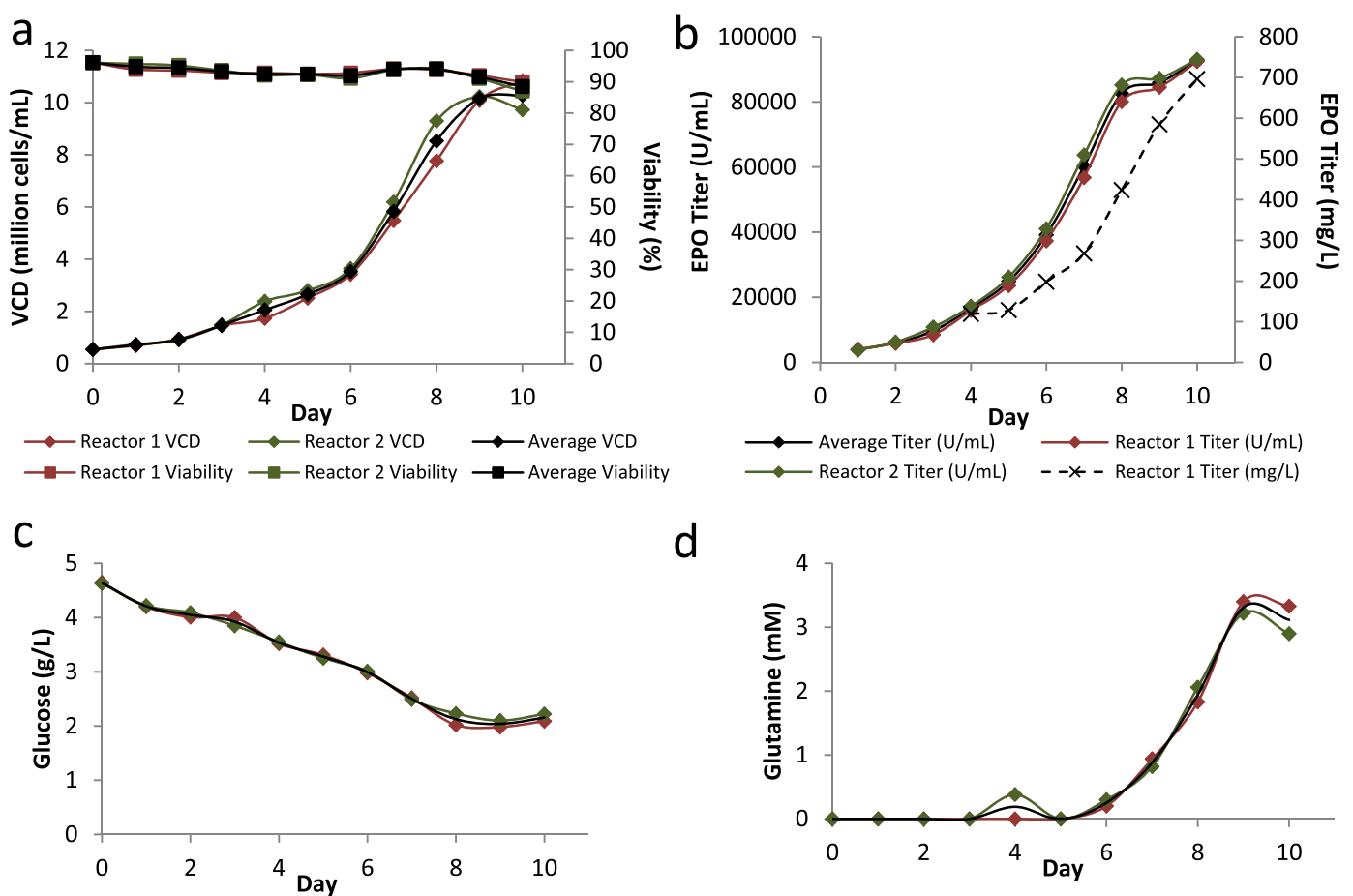

d

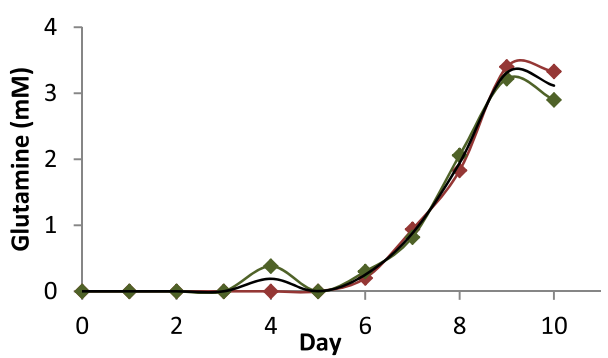

e

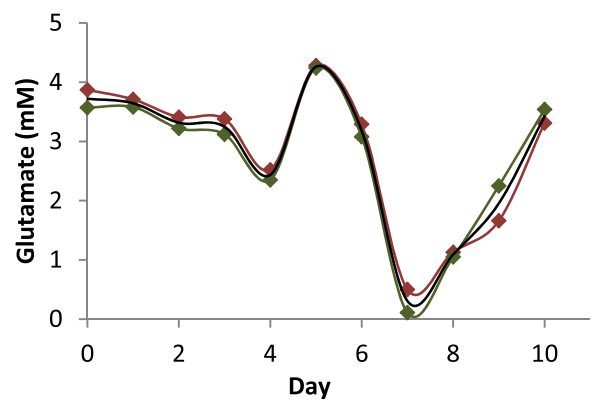

f

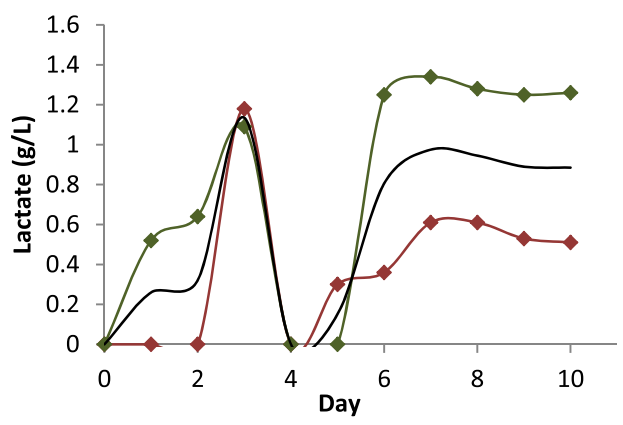

g

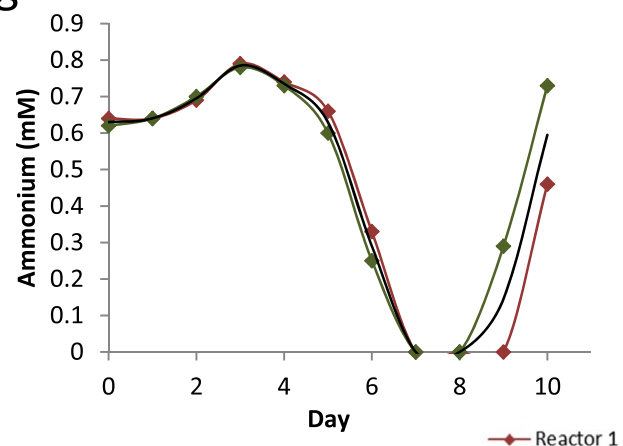

$\mathrm{h}$

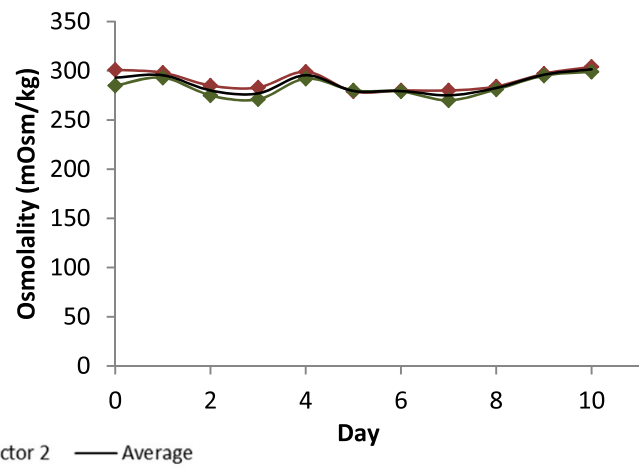

Figure 5. Productivity of HEK293 EPO producer cell pool in a $2 \mathrm{~L}$ fed-batch culture. Cell pool \#8 was cultured in $2 \mathrm{~L}$ stirred-tank bioreactors over 10 days and characterized daily for (a) viable cell density (VCD, diamonds) and viability (\%, squares). (b) EPO production was measured by ELISA over period of culture together with (c) glucose $(\mathrm{g} / \mathrm{L}),(\mathbf{d})$ glutamine $(\mathrm{mM}),(\mathbf{e})$ glutamate $(\mathrm{mM}),(\mathbf{f})$ lactate $(\mathrm{g} / \mathrm{L}),(\mathbf{g})$ ammonia $(\mathrm{mM})$, and $(\mathbf{h})$ osmolality ( $\mathrm{mOsm} / \mathrm{kg})$.

$\mathrm{CHO}^{34}$, with an average 6.6 sialic acids per mole of EPO. Notably, no alpha-Gal or Neu5Gc was detected in our HEK-derived EPO, whereas Neu5Gc was found in $4.7 \%$ of glycopeptide spectra in $\mathrm{CHO}$-derived $\mathrm{EPO}^{34}$.

The degree of sialylation was different across the sites, with Site $3>$ Site $2>$ Site 1 . The higher sialylation at Site 2 and Site 3 corresponded with these two sites having more tetra-antennary N-glycans than Site 1 and hence more substrates for sialylation by sialyltransferases. The single O-glycan site was dominated by the doubly (NeuAc2GalGalNAc) sialylated Core 1 O-glycan (Fig. 6), similar to CHO-derived $\mathrm{EPO}^{34}$. On average, EPO $\mathrm{N}$-glycans were almost fully core fucosylated, with 2.98 moles out of a possible 3.00 moles of core fucose per 


\begin{tabular}{|c|c|c|}
\hline Reference & Culture characteristics & Max EPO titer \\
\hline Restelli V et al. ${ }^{50}$ & $\begin{array}{l}\text { Suspension serum free CHO-K1 } 2.4 \mathrm{~L} \text { stirred tank culture } \\
\text { Culture length: } 7 \text { day }\end{array}$ & $2400 \mathrm{U} / \mathrm{mL}\left(\right.$ or $\left.16^{*} \mathrm{mg} / \mathrm{L}\right)$ \\
\hline Sun et al. ${ }^{51}$ & $\begin{array}{l}\text { Suspension serum free HEK } 293 \text { EBNA1 cells cultured in equal volumes of } 293 \\
\text { SFM II medium and a } 5 \times \text { amino acid solution prepared based on DMEM/F12 } \\
\text { medium formula } \\
\text { Culture length: } 10-12 \text { days }\end{array}$ & $4700 \mathrm{U} / \mathrm{mL}$ (or $33.6 \mathrm{mg} / \mathrm{L}$ ) \\
\hline Wang Z et al..$^{52}$ & $\begin{array}{l}\text { MTX amplified adherent CHO in } 12 \text {-well plate in IMDM }+10 \% \text { dFBS for } 3 \text { days, } \\
\text { followed by SFM } \\
\text { Culture length: } 6 \text { days }\end{array}$ & $8000 \mathrm{U} / \mathrm{mL}\left(\right.$ or $\left.53^{*} \mathrm{mg} / \mathrm{L}\right)$ \\
\hline Park JH et al..$^{53}$ & $\begin{array}{l}\text { Suspension serum free CHO spinner flask culture } \\
\text { Culture length: } 6 \text { days }\end{array}$ & $7000 \mathrm{U} / \mathrm{mL}\left(\right.$ or $\left.47^{*} \mathrm{mg} / \mathrm{L}\right)$ \\
\hline Our results & $\begin{array}{l}\text { Suspension serum free HEK293-GS-KO EPO } 2 \text { L stirred tank culture } \\
\text { supplemented with hydrolysate } \\
\text { Culture length: } 10 \text { days }\end{array}$ & $92700 \mathrm{U} / \mathrm{mL}$ (or $696 \mathrm{mg} / \mathrm{L})$ \\
\hline
\end{tabular}

Table 1. Comparison of EPO titers. *Estimated conversion based on $150 \mathrm{U} / \mu \mathrm{g}$, as per the 3rd International Standard by the National Institute for Biological Standards and Control (NIBSC code: 11/170).

moles EPO. The EPO glycosylation site occupancies were evaluated by determining the ratio of the abundance of the non-glycosylated peptides and the sum of their differently glycosylated counterparts. From this analysis, it was observed that EPO was completely N-glycosylated at Site 1 and Site 2 and at 99.96\% occupancy at Site 3 (Table 2).

\section{Discussion}

The use of human cell lines for production of recombinant proteins is increasing with many currently in development and some already approved. In this study, we used a GLUL ${ }^{-1-}$ HEK293 cell line with a human GLUL selection marker and MSX selection to successfully generate an EPO cell line producing high titer of EPO without non-human glycan epitopes. The use of the GLUL-MSX system abrogates issues with glutamine supplementation since glutamine is unstable and breaks down into ammonium and pyroglutamate, which at elevated concentrations results in inhibited cell growth, reduced terminal sialylation and increased glycoform heterogeneity ${ }^{35,36}$. Higher initial concentrations of glutamine has also been shown to increase ammonia concentrations in both CHO-DG44 and HEK293E cell cultures ${ }^{37}$. Our choice for disrupting the GLUL gene is to allow for regulated synthesis of glutamine and thereby ammonia, wherein eventual GLUL-transfected cells can be cultured in a glutamine-deficient media. Subsequently, GLUL expression can be selected with MSX to enhance the productivity of HEK293 cells to yield high titers of EPO. Compared to DHFR-MTX amplification, the GLUL-MSX selection system requires only a single round of selection to obtain high-expressing producer cells ${ }^{38}$. In this study, selection with $100 \mathrm{nM}$ was sufficient to achieve high titer of $92700 \mathrm{U} / \mathrm{mL}$ of EPO as analyzed by ELISA or $696 \mathrm{mg} / \mathrm{L}$ by densitometry. Further increase in yield can potentially be achieved through the addition of sodium butyrate ${ }^{39}$ or through a temperature shift from $37^{\circ} \mathrm{C}$ to $33^{\circ} \mathrm{C}$ at the stationary phase of culture (unpublished data).

Sialylation of $\mathrm{N}$-glycosylation greatly reduces clearance from the blood ${ }^{40}$. The high level of sialylation of EPO produced in HEK293 indicates that its serum half-life will be comparable to the CHO version. Glycosylation analysis also showed that Site 1 had lower degree of branching than Sites 2 and 3, which is consistent with previous report on EPO produced in $\mathrm{CHO}$ cells ${ }^{34}$. The similar pattern between $\mathrm{CHO}$ and HEK293 suggested that in both cell lines the MGAT4 and MGAT5 glycosyltransferases that add additional antennae may be sterically blocked from accessing Site 1 but not Sites 2 and 3. The similar patterns and levels of sialylation and N-glycan branching between the HEK293 derived EPO in this study and EPO from CHO suggest that EPO is subjected to similar kinds of processing in both cell lines. Importantly, these similarities also indicate that the GLUL-mediated gene selection strategy did not interfere with the glycosylation machinery but maintained the glycosylation occupancy of EPO.

It should be noted that the LacdiNAc glycan epitopes on EPO are expected for recombinant glycoproteins produced in HEK293 because this cell line expresses an active $\beta 1-4 \mathrm{~N}$-acetylgalactosaminyltransferase ${ }^{41}$. LacdiNAc is present on other glycoproteins expressed in HEK293 such as glycodelin and is not immunogenic as it is present in humans ${ }^{42}$. HEK293 is therefore able to glycosylate EPO with human glycans. Although the therapeutic implications of the higher N-glycan heterogeneity and sialylated and fucosylated LacdiNAc in EPO are not clear, these epitopes are emerging as ligands for the galectin-3, a carbohydrate binding protein secreted by immune cells and kidney cells and that can form galectin-glycoprotein lattices on the cell surface ${ }^{43-45}$. Potential binding to galectin-3 suggests that there may be a positive effect on the pharmacokinetics of EPO, such as increased half-life due to being in complex with galectin-3.

Use of human cell lines for recombinant protein production is steadily expanding with properties such as adaptability in serum-free cultures, scalability and high productivity being comparable to current non-human producer cell lines such as CHO and NSO. More importantly, human cellular expression systems do not produce immunogenic Neu5Gc and $\alpha-$ Gal epitopes which are known to impede safety and therapeutic efficacy. Human cells also have an added advantage in its capacity to produce human PTMs required for activity by complex recombinant proteins. With continued efforts in further developing human cell lines for biomanufacture, preference for a suitable host platform in the near future may transition from non-human to human cellular expression systems. 


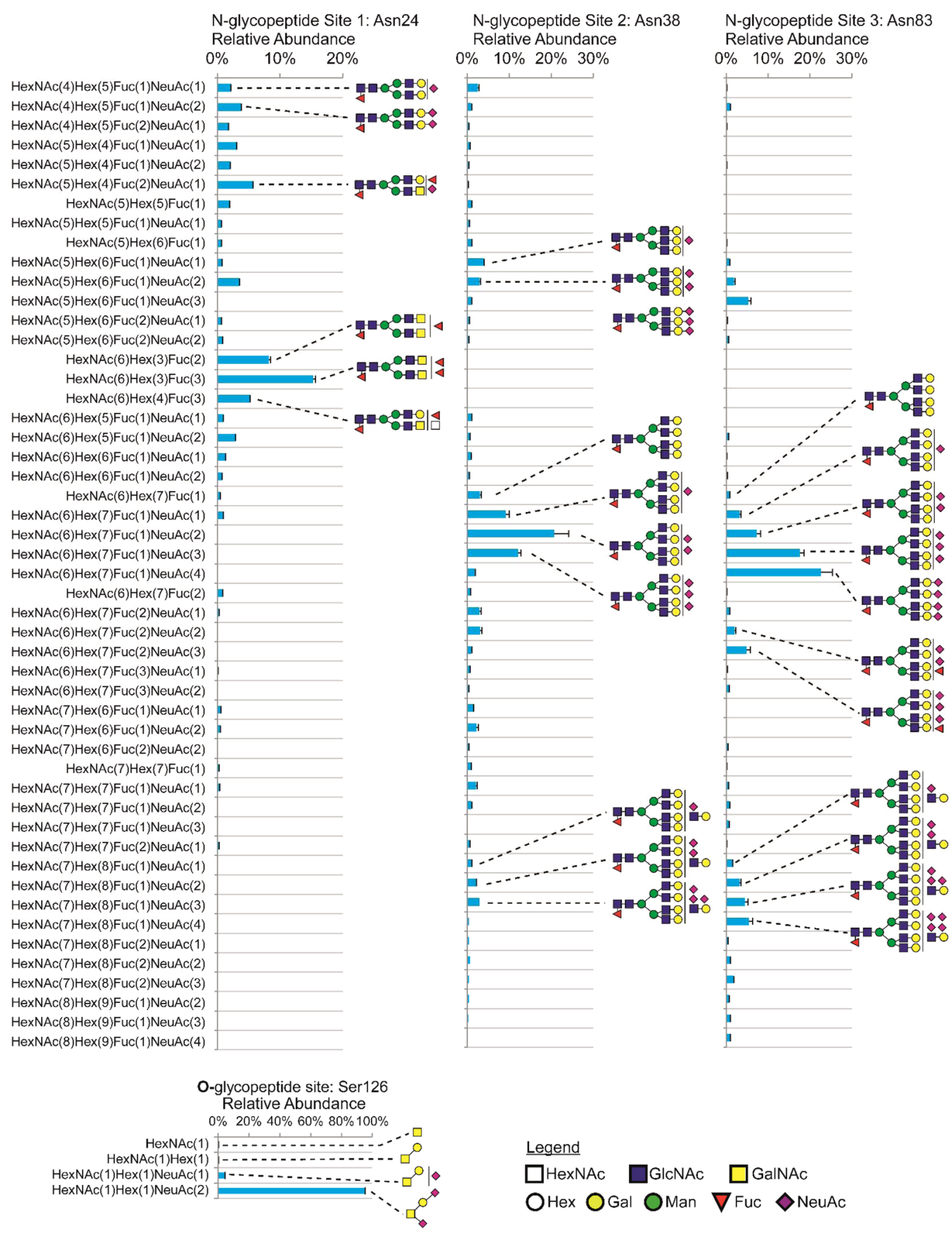

Figure 6. HEK293-derived EPO site-specific N-glycosylation. Glycopeptides from all three N-glycan sites were acquired with LCMS/MS Orbitrap HCD (normalized collisional energy 30\%) and identified using the Byonic software. Label-free quantitation was done using OpenMS/KNIME.

\section{Methods}

Cell lines and expression vectors. HEK293 cells (ATCC ${ }^{\circledR}$ CRL1573 ${ }^{\mathrm{TM}}$ ) were cultured in DMEM/F-12 (Thermo Fisher Scientific, Gibco ${ }^{\mathrm{TM}}$, Waltman, MA, USA) supplemented with $10 \%$ dialyzed FBS (Thermo Fisher Scientific, Gibco ${ }^{\mathrm{TM}}$ ) in adherent format. Knockout of glutamine synthetase (GLUL) gene by CRISPR-Cas9 was then carried out to generate four parental knockouts, GLUL ${ }^{-1-} \# 7$, \#20, \#24 and \#29. Human erythropoietin $(E P O)$ and human glutamine synthatase (GLUL) precursor genes were codon-optimized (Genscript, Piscataway, NJ, USA) and cloned into a bicistronic IRES expression vector.

Generation of GLUL-KO HEK293 cell lines via CRISPR/Cas9 system. HEK293 cells were seeded at $0.35 \times 10^{6}$ in a 6 -well plate one day prior to transfection, to ensure $~ 70-80 \%$ confluency the next day. Cas9-expressing plasmid $(6 \mu \mathrm{g})$ was co-transfected with $3 \mu \mathrm{g}$ sgRNA1-expressing and $3 \mu \mathrm{g}$ sgRNA2-expressing 


\begin{tabular}{|l|l|l|l|l|}
\hline $\begin{array}{l}\text { Glycosylation site } \\
\text { (residue) }\end{array}$ & $\begin{array}{l}\text { Core fucosylation }(\mathbf{m o l} \\
\text { core Fuc/mol EPO) }\end{array}$ & $\begin{array}{l}\text { Sialylation }(\mathbf{m o l} \\
\text { NeuAc/mol EPO) }\end{array}$ & $\begin{array}{l}\text { Antennae (\% at each } \\
\text { site) }[\text { bi/tri/tetra }]^{*}\end{array}$ & $\begin{array}{l}\text { Site Occupancy } \\
(\%)^{*}\end{array}$ \\
\hline Asn24 N-glycan & 0.9832 & 0.58 & $86.85 / 8.11 / 5.04$ & 100.00 \\
\hline Asn38 N-glycan & 0.9965 & 1.70 & $68.14 / 10.11 / 21.75$ & 100.00 \\
\hline Asn83 N-glycan & 0.9954 & 2.82 & $64.06 / 9.09 / 26.85$ & 99.96 \\
\hline Total N-glycosylation & 2.9751 & 5.10 & $73.02 / 9.11 / 17.88$ & 99.99 \\
\hline Ser126 O-glycan & Not applicable & 1.45 & Not applicable & 74.45 \\
\hline Overall glycosylation & Not applicable & 6.55 & Not applicable & 93.60 \\
\hline
\end{tabular}

Table 2. Summary of glycosylation of HEK293-derived EPO. ${ }^{\ddagger}$ Abundances of bi-/tri-/tetra-antennary structures were normalized for each $\mathrm{N}$-glycan site. Antenna \% for Total $\mathrm{N}$-glycosylation was the average of the three sites' normalized abundances. ${ }^{\varsigma}$ Moles of glycan per EPO were calculated by summing the number of NeuAc in each composition and multiplying by the relative abundance of the glycopeptide (normalized over each $\mathrm{N}$ - and O-glycosylation sites). The Total-N-glycosylation was calculated as the sum of the site specific mole ratios. *Site occupancy was defined as $100 \%$ minus the relative abundance of the unglycosylated peptide normalized for each glycan site.

plasmids using Turbofect transfection reagent (Thermo Fisher) according to the manufacturer's instructions. Successfully transfected cells were sorted by flow cytometry and plated sparsely on a $10 \mathrm{~cm}$ culture plate. Subsequently, individual clones were picked and seeded into 96-well plates (1 clone/well), and left to grow till confluency before expanding into 48 -well plates. When grown to confluency, $30 \%$ of the cells were used for gDNA extraction, while $70 \%$ were re-seeded.

Sequencing of targeted GLUL genomic locus. Genomic DNA was isolated from potential GLUL-KO cell lines using DNeasy Blood \& Tissue Kit (Qiagen, Hilden, Germany). PCR using KOD Hot-start (Merck-Novagen, Darmstadt, Germany) was then performed to amplify GLUL with primers F: $5^{\prime}$-CTCCAGAACACCTTCCACCA-3' and R: $5^{\prime}$-ACATTGCTGTCTCACCTTCC- $3^{\prime}$. Cycling conditions were programmed as follows: $95^{\circ} \mathrm{C}$ for $2 \mathrm{~min}$, followed by $35 \mathrm{cycles}$ of $95^{\circ} \mathrm{C}$ for $20 \mathrm{~s}, 55^{\circ} \mathrm{C}$ for $10 \mathrm{~s}$, and $70^{\circ} \mathrm{C}$ for $15 \mathrm{~s}$. Further extension was carried out with Taq polymerase (Thermo Fisher Scientific) to add $3^{\prime}$ adenine overhangs for cloning into a T-vector containing complementary thymidine residues. PCR products were run on a gel where single bands obtained were extracted using Gel Extraction Kit (Machery-Nagel, Düren, Germany). Cleaned PCR products were then transformed in One Shot ${ }^{\circledR}$ TOP10 Chemically Competent E. coli (Thermo Fisher Scientific) using a TOPO TA cloning kit (Thermo Fisher Scientific, Invitrogen) before plating on LB agar plates (2.5\% LB broth miller, Merck-Novagen and $1.5 \% \mathrm{BD}$ Bacto $^{\mathrm{TM}}$ Agar, Becton, Dickinson and Company, NJ, USA). Colonies were grown in $3 \mathrm{~mL}$ LB broth culture $(2.5 \%$ LB broth miller, Merck-Novagen) before plasmid extraction (QIAprep Spin Miniprep Kit, Qiagen). Purified plasmids were subsequently sequenced via the BigDye ${ }^{\circledR}$ Terminator v3.1 cycle sequencing kit carried out by $1^{\text {st }}$ Base DNA Sequencing service (Singapore).

Transcriptome analysis by RNA-seq. High throughput sequencing libraries were generated using the NEB Next Ultra II Directional RNA Library Prep Kit for Illumina together with the NEBNext Poly(A) mRNA Magnetic Isolation Module (New England Biolabs), according to manufacturer's instructions. Sequenced reads were mapped to human genome assembly hg19 using STAR with maximum number of mismatches allowed per pair (outFilterMismatchNmax) assigned to 6 and maximum number of mismatches per pair relative to read length (outFilterMismatchNoverLmx) assigned to 0.05. DESeq2 package was used to calculate the gene expression counts and perform the differential gene expression calculations. Correction of batch effects was performed using ComBat.

Development of EPO-producing HEK293 cells. GLUL $L^{-1-}$ cells were adapted to suspension culture in a DMEM/F12-based protein free-chemically defined media (PF-CDM) supplemented with $1 \times$ non-essential amino acids (NEAA) (Thermo Fisher Scientific, Gibco $^{\mathrm{TM}}$ ). Stable pools were generated via electroporation using the SG Cell Line kit in a 4D-Nucleofector system (Lonza, Basel, Switzerland). AhdI-linearized EPO expression vector $(4 \mu \mathrm{g})$ containing EPO and GLUL genes (Uniprot IDs P01588 and P15104 respectively) was transfected into $3 \times 10^{6}$ suspension $G L U L^{-1-}$ cells. Selection involved distribution of 10,000 cells per well into a 96 well plate containing glutamine-deficient DMEM/F-12 medium supplemented with $10 \%$ dialyzed serum, with further selection by supplementing with $100 \mathrm{nM}$ of methionine sulfoximine (MSX) (Merck Millipore, Burlington, MA, USA). Supernatant from growing wells were tested for EPO titer using EPO Human ELISA Kit (Thermo Fisher Scientific, Invitrogen). The highest producers were scaled up sequentially into a $125 \mathrm{~mL}$ shake flask suspension culture in PF-CDM. Five cell pools from $G L U L^{-1-} \# 7$, three cell pools from $G L U L^{-1-} \# 24$ and one cell pool from GLUL $L^{-1-} \# 20$ survived the adaptation to serum free, glutamine-deficient, PF-CDM media containing $100 \mathrm{nM}$ MSX. Surviving cell pools were then subjected to growth, productivity and stability testing analysis as described below.

Batch cell cultures. Routine suspension culture involved passaging every 3-4 days in $125 \mathrm{~mL}$ flasks (Corning, Corning, NY, USA) and growth in a shaking incubator (Kuhner, Birsfelden, Switzerland) at $37^{\circ} \mathrm{C}, 8 \%$ $\mathrm{CO} 2$ and $110 \mathrm{RPM}$. 
Growth and productivity analysis was carried out in a shake flask batch culture of $40 \mathrm{~mL}$ volume at $0.5 \times 10^{6}$ cells/mL seeding density in PF-CDM containing MSX. Sampling was carried out daily throughout the culture for analysis of viable cell density, viability, EPO titer and biochemical profile.

Stability testing was carried out by culturing the cells for 12 weeks in shake flasks at $0.5 \times 10^{6}$ cells $/ \mathrm{mL}$ seeding density in $20 \mathrm{~mL}$ of PF-CDM without MSX. During the 12 weeks, flasks were passaged twice a week and day 4 supernatants were collected for titer analysis by ELISA.

Fed-batch culture. EPO-producing HEK293 cells were scaled up in PF-CDM supplemented with animal-free Proyield Soy SE50MK-NK hydrolysate (FrieslandCampina, Amersfoort, Netherlands) and inoculated into duplicate $2 \mathrm{~L}$ glass bioreactors (Sartorius, Göttingen, Germany) at a VCD of $0.5 \times 10^{6} \mathrm{cells} / \mathrm{mL}$. Culture temperature, $\mathrm{pH}$, dissolved oxygen and stir-rate were maintained at $36.5^{\circ} \mathrm{C}, 7.0,40 \%$ and $150 \mathrm{rpm}$ respectively. Culture glucose and glutamate were topped up daily to $4 \mathrm{~g} / \mathrm{L}$ and $3 \mathrm{mM}$ respectively by feeding with a concentrated protein-free feed containing glucose and a $500 \mathrm{mM}$ glutamate solution.

Analysis of cell culture samples. To assess the health and growth of cells in culture, $0.5 \mathrm{~mL}$ of suspension cell culture was sampled on a Vi-CELL ${ }^{\mathrm{TM}}$ Cell Viability Analyzer (Beckman Coulter, Brea, CA, USA) to automatically analyse 50 images per sample using trypan blue exclusion to provide data on live cell counts and percentage viability. In addition, other key characteristics tracked during growth profiling of cell pools included $\mathrm{pH}$, glutamine, glutamate, glucose, lactate, ammonia, sodium, potassium and osmolality. These concentrations were analysed using a BioProfile ${ }^{\circledR} 400$ Analyzer (NOVA biomedical, Waltham, MA, USA) from $1 \mathrm{~mL}$ of cell-free supernatant, clarified by centrifugation at $8,000 \mathrm{rpm}$ for $10 \mathrm{mins}$.

Titer analysis. Protein productivity was tracked by regular titer analysis of cell culture supernatant using a short incubation EPO Human ELISA Kit (Thermo Fisher Scientific). Samples were diluted to a detectable range of 1.6-100 mIU/mL, before being loaded in duplicates and tested for EPO titer according to manufacturer's instructions.

For densitometry, a mg/L titer was first estimated from the U/mL titer obtained from ELISA using an estimated conversion factor of $150 \mathrm{U} / \mu \mathrm{g}$ based on the $3^{\text {rd }}$ WHO International Standard for Erythropoietin (National Institute for Biological Standards and Control, NIBSC, Herts, UK). With this $\mathrm{mg} / \mathrm{L}$ concentration, an estimated amount of EPO from each sample was run on an SDS-PAGE gel together with a commercial EPO standard from Abcam (ab215737) at different EPO loadings. The gel was then stained by Coomassie Brilliant Blue R-250 (Thermo Fisher Scientific). Intensities of each band in our gel were evaluated using ImageJ software by densitometry and compared with the standard curve generated with the Abcam EPO standard to obtain the percentage Calculated / Loaded EPO amount (Supplementary Fig. 1). These percentages were then multiplied with the mg/L titers that were estimated from ELISA U/mL titers based on $150 \mathrm{U} / \mu \mathrm{g}$, to obtain the densitometry EPO titers in $\mathrm{mg} / \mathrm{L}$.

Expression analysis. Droplet digital PCR (ddPCR) analysis. Genomic DNA (gDNA) or RNA was extracted from HEK293 wildtype, GLUL ${ }^{-1-}$ clone \#24 and EPO-producing cell pool \#8 cultured with $100 \mathrm{nM}$ MSX. Droplet digital PCR was performed using a QX100 Droplet Digital PCR system (Bio-Rad, Hercules, CA, USA). For gene copy analysis, a total volume of $20 \mu \mathrm{l}$ reaction mix containing $2 \times$ QX200 ddPCR Evagreen supermix (Bio-Rad), $150 \mathrm{nM}$ of primers (sequences shown in Supplementary Table 1), and $50 \mathrm{ng}$ of gDNA in nuclease-free water was prepared. To perform mRNA ddPCR analysis, $500 \mathrm{ng}$ of RNA was first converted into cDNA using iScript Reverse Transcription Supermix (Bio-Rad). Complementary DNA $(2 \mu \mathrm{l})$ was mixed into the ddPCR reaction as per gene copy analysis.

Samples were then transferred to the DG8 cartridge, together with $70 \mu \mathrm{l}$ of oil into its lower wells, before being loaded into the QX200 droplet generator (Bio-Rad). The droplet mixture $(40 \mu \mathrm{l})$ from each sample was transferred to a 96-well PCR plate, sealed with the Bio-Rad PX1 PCR plate sealer and inserted into the C1000 thermal cycler (Bio-Rad). Cycling conditions using EvaGreen assay were programmed as follows: $95^{\circ} \mathrm{C}$ for $5 \mathrm{~min}, 95^{\circ} \mathrm{C}$ for 40 cycles at $30 \mathrm{~s}$ per cycle $58^{\circ} \mathrm{C}$ for $1 \mathrm{~min}$, followed by $4^{\circ} \mathrm{C}$ for $10 \mathrm{~min}$ and $90^{\circ} \mathrm{C}$ for $5 \mathrm{~min}$. A ramp rate of $2^{\circ} \mathrm{C} / \mathrm{s}$ was used for the entire cycling process. Following, the plate was assessed in the QX200 droplet reader for completed PCR reactions in individual droplets and the data was analyzed using the QuantaSoft software (Bio-Rad). Thresholds for determining positive droplets were established manually based on wells containing water alone which served as negative controls. The number of copies of the gene of interest per ng of input gDNA or RNA was then calculated as below.

$$
\text { Copies per ng gDNA or RNA }=\text { Copies per } 20 \mu l / \text { Input gDNA or RNA amount }
$$

To determine genomic copy count, PDHA2 was used as a reference locus, where number of copies in HEK293 wildtype genome was determined to be 2 . Other genes characterized relative to PDHA2 include PDHA1 and SERPINA1 which both contain 3 copies each in the HEK293 wildtype genome, synonymous to a previous study ${ }^{46}$. The following formula was then used to determine genomic copy count of target genes:

Genomic copy per cell $=($ Copies per ng gDNA of target/Copies per ng gDNA of PDHA2 reference $) \times 2$

Western blotting. To detect GLUL by immunoblotting, cell pellets were first homogenized in phosphatase inhibitor lysis buffer. Lysed cell pellets were then diluted in LDS sample buffer and heated in reducing agent prior to loading onto the gel for Western blotting as previously described ${ }^{29}$. To detect EPO, culture supernatant were similarly diluted and reduced prior to loading and immunoblotting. Blots were incubated with antibodies: anti-EPO 
(1:1000; MAB2871, R\&D systems, MN, USA), anti-GLUL (1:5000; MAB302, Merck Millipore) and anti-actin (Fig. 1b: sc-47778, Santa Cruz, RX, USA; Figs 1f and 4c: 1:6000; A2066, Sigma-Aldrich, MO, USA). Figure 1b was imaged using ChemiDoc (Bio-Rad), while Figs 1f and 4c were imaged on a chemiluminescent CCD camera, ImageQuant LAS 500 (GE, MA, USA). Full length gel images are shown in Supplementary Table and Figures File.

Glycosylation analysis. HEK-derived EPO was harvested from a bioreactor fed-batch culture (Fig. 5, Reactor 1) on day 10 at a viable cell density of 10.8 million cells $/ \mathrm{ml}$ and culture viability of $89.9 \%$. A two-step purification protocol was performed consisting of ion exchange chromatography followed by size exclusion chromatography on an ÄKTA Purifier 10 FPLC system (GE Healthcare) connected to Frac-950 (GE Healthcare). Culture supernatant was adjusted to $\mathrm{pH}$ of 8.0 and conductivity of $4 \mathrm{mS} / \mathrm{cm}$ before loading onto a HiTrap Capto Q (GE Healthcare) column pre-equilibrated with $50 \mathrm{mM}$ Tris, $\mathrm{pH}$ 8.0. Column was subsequently washed with the same equilibration buffer before elution of $\mathrm{EPO}$ at $150 \mathrm{mM} \mathrm{NaCl}$ in $50 \mathrm{mM}$ Tris, $\mathrm{pH} 8.0$ and flow rate of $1 \mathrm{~mL} / \mathrm{min}$. Peak fractions were collected and verified to contain EPO by SDS-PAGE prior to concentration with Amicon Ultra-15 $10 \mathrm{~K}$ (Merck-Millipore). The concentrated fraction was then injected into a HiLoad 16/600 Superdex 75 pg (GE Healthcare) equilibrated with $1 \mathrm{x}$ PBS buffer. Utilizing a $1 \mathrm{~mL} / \mathrm{min}$ flow rate of PBS buffer, peak fractions were collected and combined before determining purified titer using an EPO ELISA kit (ThermoFisher Scientific). The purified EPO were denatured reduced, alkylated with iodoacetic acid and digested with trypsin (1:50 weight ratio, sequencing grade, Promega, WI, USA) and GluC (1:50 weight ratio, sequencing grade, Promega), using a filter aided sample preparation method described previously ${ }^{47}$.

nanoLC-MS analysis of samples. Approximately $2.5 \mu \mathrm{g}$ of glycopeptides were injected (Dionex Ultimate WPS3000 RSLCnano) and desalted on a C18 PepMap100 trap column ( $5 \mu \mathrm{m}$ particle size, $10 \mathrm{~nm}$ pore size, $300 \mu \mathrm{m}$ I.D., $5 \mathrm{~mm}$ length, Thermo Fisher Scientific) and separated on a nanoflow EASY-Spray PepMap RSLC C18 column ( $2 \mu \mathrm{m}$ particle size, $10 \mathrm{~nm}$ pore size, $50 \mu \mathrm{m}$ internal diameter, $150 \mathrm{~mm}$ length, Thermo Fisher Scientific) at $40^{\circ} \mathrm{C}$ using a 104 min linear gradient from $2 \%$ to $50 \%$ acetonitrile in LCMS-grade water (Merck) with $0.1 \%$ formic acid (>98\% purity, Merck) at $300 \mathrm{~nL} / \mathrm{min}$. The eluting peptides were analysed with an Orbitrap Fusion Tribrid (Thermo Fisher Scientific) with the following parameters: spray voltage at $+2000 \mathrm{~V}$, ion transfer tube at $300{ }^{\circ} \mathrm{C}$, with no sweep gas. Full profile scans used the Orbitrap at 120,000 resolution, $m / z 300-3000$ range with a maximum injection time of $70 \mathrm{~ms}$, using quadrupole isolation. MS/MS was triggered for peptides of charge state 2-6, intensity more than $5.0 \mathrm{e} 4$ and apex detected as $35 \%$ of the full width at half maximum (FWHM) of a gaussian peak of 12 seconds FWHM. An exclusion list was constructed by combining all the peaks from the negative control gel pieces, a blank run and BSA. Dynamic exclusion of 30 seconds was applied. MS/MS fragmentation done using higher collisional dissociation (HCD) with normalized stepped collisional energy of $30 \pm 5 \%$ and fragments were detected with the Orbitrap operating at 30,000 resolution and a maximum injection time of $100 \mathrm{~ms}$.

Glycoproteomic data analysis. LCMS data files were analyzed by commercial software Byonic (ProteinMetrics ver. w2.14-27) and aided by the GlycopeptideGraphMS software ${ }^{48}$. Data files were imported into Byonic and the following search settings were used: fully specific cleavage C-terminal of arginine, lysine, aspartic acid and glutamic acid, three missed cleavages, precursor mass tolerance $10 \mathrm{ppm}$, fragment mass tolerance $10 \mathrm{ppm}$, up to two common modifications were allowed of variable methionine oxidation, fixed cysteine carboxymethylation, up to one rare modifications was allowed from either one $\mathrm{N}$-glycan from a library developed for HEK293, or one O-glycan from the 6 most common structures, and the protein list was the SWISSPROT database. In this way, glycopeptides were identified by searching their MS/MS fragmentation for oxonium ions, peptide sequence ions (b-and y-ions) and glycan neutral losses (B- and Y-ions) as well as the complete intact mass of the glycopeptide.

The abundances of identified glycopeptides were computed using an OpenMS pipeline, which involved integrating the area under the extracted ion chromatogram for all detected charge states, grouping them into LCMS features, and deconvoluting ${ }^{49}$. Redundant glycopeptides (i.e. spanning the same glycan site but with missed cleavages) were grouped together for site-specific analyses. LacdiNAc was deemed to be present if either the composition allowed for pairs of unoccupied HexNAc after placing all non-core Hex in LacNAc antennae or if the $m / z 407.1658$ oxonium ion [HexNAc2 $+\mathrm{H}]^{+}$was present. The glycan features of EPO were quantified as follows: the first fucose was always assigned as core fucosylation and the relative abundances (normalized to overall $\mathrm{N}$-glycosylation) of glycopeptides with core fucose was summed and divided by 100 to give the mol core fucose / mol EPO; sialylation and total fucosylation was derived by multiplying the relative abundance (normalized to overall N-glycosylation) by the number of NeuAc, then summing the results; branching was calculated per site by separately summing the abundances of mono-, bi-, tri- and tetra-antennary structures; site occupancy was calculated as $100 \%$ minus the relative abundance (normalised to each site) of the unglycosylated peptide.

Calculations. Specific growth rate $(\mu)$ was determined by plotting $\ln (\mathrm{VCD})$ vs $t$ according to Eq. 1 , where $\mathrm{VCD}$ is the viable cell density, $\mathrm{VCD}_{0}$ is the initial viable cell density and $\mathrm{t}$ is the culture time.

$$
\begin{aligned}
& \mathrm{VCD}=\mathrm{VCD}_{0} \mathrm{e}^{\mu \mathrm{t}} \\
& \ln \left(\mathrm{VCD} / \mathrm{VCD}_{0}\right)=\mu \mathrm{t}
\end{aligned}
$$

The cumulative integrated viable cell density (IVCD) was calculated by trapezium rule according to Eq. 2 .

$$
\mathrm{IVCD}_{\mathrm{t}}=\mathrm{IVCD}_{\mathrm{t}-1}+0.5 \times\left(\mathrm{VCD}_{\mathrm{t}}+\mathrm{VCD}_{\mathrm{t}-1}\right) \times \Delta \mathrm{t}
$$


Specific EPO productivity $\left(q_{p}\right)$ between culture times $t_{1}$ and $t_{2}$ was determined by plotting IgG titer $(P)$ vs IVCD according to Eq. 3.

$$
\begin{aligned}
& \mathrm{q}_{\mathrm{p}}=\left(\mathrm{P}_{\mathrm{t} 2}-\mathrm{P}_{\mathrm{t} 1}\right) /\left(\mathrm{IVCD}_{\mathrm{t} 2}-\operatorname{IVCD}_{\mathrm{t} 1}\right) \\
& \mathrm{P}_{\mathrm{t} 2}=\mathrm{q}_{\mathrm{p}} \times\left(\mathrm{IVCD}_{\mathrm{t} 2}-\mathrm{IVCD}_{\mathrm{t} 1}\right)+\mathrm{P}_{\mathrm{t} 1}
\end{aligned}
$$

\section{Data availability}

The RNA-seq data generated in the current study will be deposited in the NCBI GEO database and made publicly available upon acceptance of the manuscript.

Received: 17 January 2019; Accepted: 31 October 2019;

Published online: 14 November 2019

\section{References}

1. Walsh, G. Biopharmaceutical benchmarks 2014. Nat Biotechnol 32, 992-1000, https://doi.org/10.1038/nbt.3040 (2014).

2. Dumont, J., Euwart, D., Mei, B., Estes, S. \& Kshirsagar, R. Human cell lines for biopharmaceutical manufacturing: history, status, and future perspectives. Crit Rev Biotechnol 36, 1110-1122, https://doi.org/10.3109/07388551.2015.1084266 (2016).

3. Lalonde, M. E. \& Durocher, Y. Therapeutic glycoprotein production in mammalian cells. J Biotechnol 251, 128-140, https://doi. org/10.1016/j.jbiotec.2017.04.028 (2017).

4. Zhu, J. Mammalian cell protein expression for biopharmaceutical production. Biotechnol Adv 30, 1158-1170, https://doi. org/10.1016/j.biotechadv.2011.08.022 (2012).

5. Lai, T., Yang, Y. \& Ng, S. K. Advances in Mammalian cell line development technologies for recombinant protein production. Pharmaceuticals (Basel) 6, 579-603, https://doi.org/10.3390/ph6050579 (2013).

6. Goh, J. B. \& Ng, S. K. Impact of host cell line choice on glycan profile. Crit Rev Biotechnol 38, 851-867, https://doi.org/10.1080/073 88551.2017.1416577 (2018)

7. Ghaderi, D., Taylor, R. E., Padler-Karavani, V., Diaz, S. \& Varki, A. Implications of the presence of N-glycolylneuraminic acid in recombinant therapeutic glycoproteins. Nat Biotechnol 28, 863-867, https://doi.org/10.1038/nbt.1651 (2010).

8. Fliedl, L., Grillari, J. \& Grillari-Voglauer, R. Human cell lines for the production of recombinant proteins: on the horizon. $N$ Biotechnol 32, 673-679, https://doi.org/10.1016/j.nbt.2014.11.005 (2015).

9. Berkner, K. L. Expression of recombinant vitamin K-dependent proteins in mammalian cells: factors IX and VII. Methods Enzymol 222, 450-477 (1993).

10. Kannicht, C. et al. Characterisation of the post-translational modifications of a novel, human cell line-derived recombinant human factor VIII. Thromb Res 131, 78-88, https://doi.org/10.1016/j.thromres.2012.09.011 (2013).

11. Peters, R. T. et al. Biochemical and functional characterization of a recombinant monomeric factor VIII-Fc fusion protein. J Thromb Haemost 11, 132-141, https://doi.org/10.1111/jth.12076 (2013).

12. Thomas, P. \& Smart, T. G. HEK293 cell line: a vehicle for the expression of recombinant proteins. J Pharmacol Toxicol Methods 51, 187-200, https://doi.org/10.1016/j.vascn.2004.08.014 (2005).

13. Meissner, P. et al. Transient gene expression: recombinant protein production with suspension-adapted HEK293-EBNA cells. Biotechnol Bioeng 75, 197-203 (2001).

14. Loignon, M. et al. Stable high volumetric production of glycosylated human recombinant IFNalpha2b in HEK293 cells. BMC Biotechnol 8, 65, https://doi.org/10.1186/1472-6750-8-65 (2008).

15. Spidel, J. L., Vaessen, B., Chan, Y. Y., Grasso, L. \& Kline, J. B. Rapid high-throughput cloning and stable expression of antibodies in HEK293 cells. J Immunol Methods 439, 50-58, https://doi.org/10.1016/j.jim.2016.09.007 (2016).

16. Fan, L. et al. Improving the efficiency of $\mathrm{CHO}$ cell line generation using glutamine synthetase gene knockout cells. Biotechnol Bioeng 109, 1007-1015, https://doi.org/10.1002/bit.24365 (2012).

17. Yu, D. Y., Noh, S. M. \& Lee, G. M. Limitations to the development of recombinant human embryonic kidney 293E cells using glutamine synthetase-mediated gene amplification: Methionine sulfoximine resistance. J Biotechnol 231, 136-140, https://doi. org/10.1016/j.jbiotec.2016.06.003 (2016).

18. Yu, D. Y., Lee, S. Y. \& Lee, G. M. Glutamine synthetase gene knockout-human embryonic kidney 293E cells for stable production of monoclonal antibodies. Biotechnol Bioeng 115, 1367-1372, https://doi.org/10.1002/bit.26552 (2018).

19. Brogna, S. \& Wen, J. Nonsense-mediated mRNA decay (NMD) mechanisms. Nat Struct Mol Biol 16, 107-113, https://doi. org/10.1038/nsmb.1550 (2009).

20. Brown, M. E., Renner, G., Field, R. P. \& Hassell, T. Process development for the production of recombinant antibodies using the glutamine synthetase (GS) system. Cytotechnology 9, 231-236 (1992).

21. Love, M. I., Huber, W. \& Anders, S. Moderated estimation of fold change and dispersion for RNA-seq data with DESeq. 2. Genome Biol 15, 550, https://doi.org/10.1186/s13059-014-0550-8 (2014).

22. Huang, D. W. et al. DAVID Bioinformatics Resources: expanded annotation database and novel algorithms to better extract biology from large gene lists. Nucleic Acids Res 35, W169-175, https://doi.org/10.1093/nar/gkm415 (2007).

23. Ronzio, R. A., Rowe, W. B. \& Meister, A. Studies on the mechanism of inhibition of glutamine synthetase by methionine sulfoximine. Biochemistry 8, 1066-1075 (1969).

24. Noh, S. M., Shin, S. \& Lee, G. M. Comprehensive characterization of glutamine synthetase-mediated selection for the establishment of recombinant CHO cells producing monoclonal antibodies. Sci Rep 8, 5361, https://doi.org/10.1038/s41598-018-23720-9 (2018).

25. Feary, M., Racher, A. J., Young, R. J. \& Smales, C. M. Methionine sulfoximine supplementation enhances productivity in GSCHOK1SV cell lines through glutathione biosynthesis. Biotechnol Prog 33, 17-25, https://doi.org/10.1002/btpr.2372 (2017).

26. Laubach, V. E., Garvey, E. P. \& Sherman, P. A. High-level expression of human inducible nitric oxide synthase in Chinese hamster ovary cells and characterization of the purified enzyme. Biochem Biophys Res Commun 218, 802-807, https://doi.org/10.1006/ bbrc.1996.0143 (1996).

27. Jun, S. C., Kim, M. S., Hong, H. J. \& Lee, G. M. Limitations to the development of humanized antibody producing Chinese hamster ovary cells using glutamine synthetase-mediated gene amplification. Biotechnol Prog 22, 770-780, https://doi.org/10.1021/ bp060004t (2006).

28. Ng, S. K. et al. Production of functional soluble Dectin-1 glycoprotein using an IRES-linked destabilized-dihydrofolate reductase expression vector. PLoS One 7, e52785, https://doi.org/10.1371/journal.pone.0052785 (2012).

29. Chin, C. L., Chin, H. K., Chin, C. S., Lai, E. T. \& Ng, S. K. Engineering selection stringency on expression vector for the production of recombinant human alphal-antitrypsin using Chinese Hamster ovary cells. BMC Biotechnol 15, 44, https://doi.org/10.1186/ s12896-015-0145-9 (2015). 
30. de la Cruz Edmonds, M. C. et al. Development of transfection and high-producer screening protocols for the CHOK1SV cell system. Mol Biotechnol 34, 179-190 (2006).

31. Bailey, L. A., Hatton, D., Field, R. \& Dickson, A. J. Determination of Chinese hamster ovary cell line stability and recombinant antibody expression during long-term culture. Biotechnol Bioeng 109, 2093-2103 (2012).

32. Barnes, L. M., Bentley, C. M. \& Dickson, A. J. Characterization of the stability of recombinant protein production in the GS-NS0 expression system. Biotechnol Bioeng 73, 261-270 (2001).

33. Noh, S. M., Park, J. H., Lim, M. S., Kim, J. W. \& Lee, G. M. Reduction of ammonia and lactate through the coupling of glutamine synthetase selection and downregulation of lactate dehydrogenase-A in CHO cells. Appl Microbiol Biotechnol 101, 1035-1045, https://doi.org/10.1007/s00253-016-7876-y (2017).

34. Jiang, J. et al. Site-specific qualitative and quantitative analysis of the $\mathrm{N}$ - and O-glycoforms in recombinant human erythropoietin. Anal Bioanal Chem 406, 6265-6274, https://doi.org/10.1007/s00216-014-8037-8 (2014).

35. Hansen, H. A. \& Emborg, C. Influence of ammonium on growth, metabolism, and productivity of a continuous suspension Chinese hamster ovary cell culture. Biotechnol Prog 10, 121-124, https://doi.org/10.1021/bp00025a014 (1994).

36. Reuveny, S., Velez, D., Macmillan, J. D. \& Miller, L. Factors affecting cell growth and monoclonal antibody production in stirred reactors. J Immunol Methods 86, 53-59 (1986).

37. Rajendra, Y., Kiseljak, D., Baldi, L., Hacker, D. L. \& Wurm, F. M. Influence of glutamine on transient and stable recombinant protein production in CHO and HEK-293 cells. BMC Proc 5(Suppl 8), P35, https://doi.org/10.1186/1753-6561-5-S8-P35 (2011).

38. Kingston, R. E., Kaufman, R. J., Bebbington, C. R. \& Rolfe, M. R. Amplification using CHO cell expression vectors. Curr Protoc Mol Biol Chapter 16, Unit 16 23, https://doi.org/10.1002/0471142727.mb1623s60 (2002).

39. Wang, Q. et al. Combining Butyrated ManNAc with Glycoengineered CHO Cells Improves EPO Glycan Quality and Production. Biotechnol J, e1800186, https://doi.org/10.1002/biot.201800186 (2018).

40. Baenziger, J. U., Kumar, S., Brodbeck, R. M., Smith, P. L. \& Beranek, M. C. Circulatory half-life but not interaction with the lutropin/ chorionic gonadotropin receptor is modulated by sulfation of bovine lutropin oligosaccharides. Proc Natl Acad Sci USA 89, 334-338 (1992).

41. Van den Nieuwenhof, I. M. et al. Recombinant glycodelin carrying the same type of glycan structures as contraceptive glycodelin-A can be produced in human kidney 293 cells but not in chinese hamster ovary cells. Eur J Biochem 267, 4753-4762 (2000).

42. Dell, A. et al. Structural analysis of the oligosaccharides derived from glycodelin, a human glycoprotein with potent immunosuppressive and contraceptive activities. J Biol Chem 270, 24116-24126 (1995).

43. Bocker, S., Laaf, D. \& Elling, L. Galectin Binding to Neo-Glycoproteins: LacDiNAc Conjugated BSA as Ligand for Human Galectin-3. Biomolecules 5, 1671-1696, https://doi.org/10.3390/biom5031671 (2015).

44. Garner, O. B. \& Baum, L. G. Galectin-glycan lattices regulate cell-surface glycoprotein organization and signalling. Biochem Soc Trans 36, 1472-1477, https://doi.org/10.1042/BST0361472 (2008).

45. Bumba, L. et al. Poly-N-Acetyllactosamine Neo-Glycoproteins as Nanomolar Ligands of Human Galectin-3: Binding Kinetics and Modeling. Int J Mol Sci 19, https://doi.org/10.3390/ijms19020372 (2018).

46. Lin, Y. C. et al. Genome dynamics of the human embryonic kidney 293 lineage in response to cell biology manipulations. Nat Commun 5, 4767, https://doi.org/10.1038/ncomms5767 (2014).

47. Wisniewski, J. R., Zougman, A., Nagaraj, N. \& Mann, M. Universal sample preparation method for proteome analysis. Nat Methods 6, 359-362, https://doi.org/10.1038/nmeth.1322 (2009).

48. Choo, M. S., Wan, C., Rudd, P. M. \& Nguyen-Khuong, T. GlycopeptideGraphMS: Improved Glycopeptide Detection and Identification by Exploiting Graph Theoretical Patterns in Mass and Retention Time. Anal Chem 91, 7236-7244, https://doi. org/10.1021/acs.analchem.9b00594 (2019).

49. Pfeuffer, J. et al. OpenMS - A platform for reproducible analysis of mass spectrometry data. J Biotechnol 261, 142-148, https://doi. org/10.1016/j.jbiotec.2017.05.016 (2017).

50. Restelli, V. et al. The effect of dissolved oxygen on the production and the glycosylation profile of recombinant human erythropoietin produced from CHO cells. Biotechnol Bioeng 94, 481-494, https://doi.org/10.1002/bit.20875 (2006).

51. Sun, X., Goh, P. E., Wong, K. T., Mori, T. \& Yap, M. G. Enhancement of transient gene expression by fed-batch culture of HEK 293 EBNA1 cells in suspension. Biotechnol Lett 28, 843-848, https://doi.org/10.1007/s10529-006-9010-1 (2006).

52. Wang, Z., Park, J. H., Park, H. H., Tan, W. \& Park, T. H. Enhancement of recombinant human EPO production and sialylation in chinese hamster ovary cells through Bombyx mori 30Kc19 gene expression. Biotechnol Bioeng 108, 1634-1642, https://doi. org/10.1002/bit.23091 (2011).

53. Park, J. H. et al. Enhancement of recombinant human EPO production and glycosylation in serum-free suspension culture of CHO cells through expression and supplementation of 30Kc19. Appl Microbiol Biotechnol 96, 671-683, https://doi.org/10.1007/s00253012-4203-0 (2012).

\section{Acknowledgements}

This work was supported by the Biomedical Research Council (BMRC) of the Agency for Science, Technology and Research (A*STAR), Singapore, and Biological Design Tools and Applications Funding scheme funded by the National Research Foundation (NRF2013-THE001-093), Singapore. Glycan analysis work was supported by the Strategic Positioning Fund (SPF) ("GlycoSing") from the BMRC of A*STAR and A*STAR's Joint Council Office Visiting Investigator Programme ("HighGlycoART”).

\section{Author contributions}

M.H.T. and S.K.N. conceived project and designed the experiments. C.L.C., J.B.G., H.S., K.I.L., A.G., R.S., H.L.L., A.T. and T.W.Q. performed the experiments. M.C. and T.N.K. performed the glycosylation profile analyses. All authors analyzed the generated data. All authors contributed to and reviewed the manuscript.

\section{Competing interests}

The authors are funded by A*STAR, and access to materials described in the work may be subject to terms stipulated by the agency.

\section{Additional information}

Supplementary information is available for this paper at https://doi.org/10.1038/s41598-019-53391-z.

Correspondence and requests for materials should be addressed to M.H.T. or S.K.N.

Reprints and permissions information is available at www.nature.com/reprints. 
Publisher's note Springer Nature remains neutral with regard to jurisdictional claims in published maps and institutional affiliations.

(c) (i) Open Access This article is licensed under a Creative Commons Attribution 4.0 International License, which permits use, sharing, adaptation, distribution and reproduction in any medium or format, as long as you give appropriate credit to the original author(s) and the source, provide a link to the Creative Commons license, and indicate if changes were made. The images or other third party material in this article are included in the article's Creative Commons license, unless indicated otherwise in a credit line to the material. If material is not included in the article's Creative Commons license and your intended use is not permitted by statutory regulation or exceeds the permitted use, you will need to obtain permission directly from the copyright holder. To view a copy of this license, visit http://creativecommons.org/licenses/by/4.0/.

(c) The Author(s) 2019 